\title{
A Comprehensive Molecular Portrait of Human Urine-derived Renal Progenitor Cells
}

Md Shaifur Rahman*, Wasco Wruck*, Lucas-Sebastian Spitzhorn, Martina Bohndorf, Soraia Martins, Fatima Asar, Audrey Ncube, Lars Erichsen, Nina Graffmann, James Adjaye ${ }^{\#}$

Institute for Stem Cell Research and Regenerative Medicine, Medical Faculty, Heinrich Heine University Düsseldorf, 40225 Düsseldorf, Germany

\section{*Equal contribution}

Md Shaifur Rahman: shaifur.rahman@med.uni-duesseldorf.de

Wasco Wruck: wasco.wruck@med.uni-duesseldorf.de

Lucas-Sebastian Spitzhorn: lucas-sebastian.spitzhorn@uni-duesseldorf.de

Martina Bohndorf: martina.bohndorf@uni-duesseldorf.de

Audrey Ncube: Audrey.Ncube@med.uni-duesseldorf.de

Soraia Martins: Soraia.Martins@med.uni-duesseldorf.de

Fatima Asar: fatima.asar@stud.uni-due.de

Lars Erichsen: Lars.Erichsen@uni-duesseldorf.de

Nina Graffmann: nina.graffmann@med.uni-duesseldorf.de

James Adjaye: james.adjaye@med.uni-duesseldorf.de

Running title: Urine-derived Renal Progenitors

\section{\#Correspondence}

Prof. Dr. James Adjaye

Email: james.adjaye@med.uni-duesseldorf.de

Phone: 00492118108191

Key words: kidney, urine, renal progenitor cells, self-renewal, gene regulatory networks, WNT, TGF $\beta$, SIX2, JUN. 


\section{Significance Statement}

Human urine is a non-invasive source of stem cells with regeneration potential. Here, we investigated the cellular and molecular identities, and the gene regulation driving self-renewal and differentiation of these cells in vitro. These cells express pluripotency-associated markers enabling easy reprogramming. Based on the expression of renal associated genes, proteins and functionality, we refer to these cells as urine derived renal progenitor cellsUdRPCs. CHIR99021-induced differentiation of UdRPCs activated WNT-related genesAXIN2, JUN and NKD1. Protein interaction network identified JUN as a putative regulator of differentiation whereas self-renewal is maintained by FGF2-driven TGF $\beta$-SMAD2/3. Our data will enhance understanding of the molecular identities of UdRPCs, and enable the generation of renal disease models in vitro and eventually kidney-associated regenerative therapies. 


\section{Abstract}

Background Human urine is now recognised as a non-invasive source of stem cells with regeneration potential. These cells are mesenchymal stem cells but their detailed molecular and cellular identities are poorly defined. Furthermore, unlike the mouse, the gene regulatory network driving self-renewal and differentiation into functional renal cells in vitro remain unresolved.

Methods We isolated urine stem cells from 10 individuals from both genders and distinct ages, characterized them as renal progenitor cells and explored the gene regulatory network sustaining self-renewal.

Results These cells express pluripotency-associated proteins- TRA-1-60, TRA-1-81, SSEA4, C-KIT and CD133. Expression of pluripotency-associated proteins enabled rapid reprogramming into iPSCs using episomal-based plasmids without pathway perturbations. Transcriptome analysis revealed expression of a plethora of nephrogenesis-related genes such as SIX2, OSR1, CITED1, NPHS2, NPHS1, PAX2, SALL1, AQP2, EYA1, SLC12A1 and $U M O D$. As expected, the cells transport Albumin by endocytosis. Based on this, we refer to these cells as urine derived renal progenitor cells- UdRPCs. Associated GO-term analysis of UdRPCs and UdRPC-iPSCs underlined their renal identity and functionality. Upon differentiation by WNT activation using the GSK3 $\beta$-inhibitor (CHIR99021), transcriptome and KEGG pathway analysis revealed upregulation of WNT-associated genes-AXIN2, JUN and NKD1. Protein interaction network identified JUN- a downstream target of the WNT pathway in association with STAT3, ATF2 and MAPK1 as a putative regulator of self-renewal and differentiation in UdRPCs. Furthermore, like pluripotent stem cells, self-renewal is maintained by FGF2-driven TGF $\beta-S M A D 2 / 3$ pathway.

Conclusion This in vitro model and the data presented should lay the foundation for studying nephrogenesis in man.

Key words: Kidney, urine, renal progenitor cells, iPSCs, self-renewal, nephrogenesis, WNT, TGF $\beta$, SIX2, JUN. 


\section{Introduction}

Approximately 2000 to 7000 cells are flushed out of the renal system in our urine, which contain cells of epithelial origin, erythrocytes, leukocytes, neutrophils, lymphocytes and a rare population renal stem cells. ${ }^{1}$ Urine stem cells which originate from the metanephric mesenchyme ( $\mathrm{MM}$ ) and those from the glomeruli are capable of giving rise to podocytes, proximal tubular cells and distal cells. These progenitor cells express renal markers such as PAX2, PAX8, ${ }^{2}$ SYNPO, NPHS1, PODXL and NPHS2. ${ }^{3}$ Interestingly, these cells exhibit stem cell properties, i.e. expression of pluripotency-associated markers such as TRA-1-60, TRA-181, SSEA4, C-KIT (CD117), CD133 and SSEA4; and possess high proliferation capacity as they show telomerase activity. Further, they endow multi-differentiation potential and like bone marrow derived mesenchymal stem cells express Vimentin, CD105, CD90, CD73 and not the hematopoietic stem cell markers- CD14, CD31, CD34 and CD45..$^{4,5}$ Studies in mice have shown that Osr1, Six2, Wnt and Wt1 are required to maintain renal progenitor cells during kidney organogenesis. ${ }^{6,7,8,9,10,11}$ Additionally, signalling pathways such as Wnt, Fgf, $\operatorname{Tgf} \beta$ and Notch play major roles in renal stem cell maintenance and differentiation. ${ }^{12,13,14,15}$

The transcription factor, Odd-skipped related 1 (Osr1), is an early marker specific for the intermediate mesenchyme (IM); knockout mice lack renal structures due to the failure to form the $\mathrm{IM}^{16}$ The homeodomain transcriptional regulator Six2 is expressed in the cap mesenchyme (CM) originating from MM. Six2 positive populations can generate all cell types of the main body of the nephron. ${ }^{17}$ Inactivation of Six2 results in premature and ectopic renal vesicles, leading to a reduced number of nephrons and to renal hypoplasia. ${ }^{18}$ Mechanistically, Osr1 plays a crucial role in Six2-dependent maintenance of mouse nephron progenitors by antagonizing Wnt-directed differentiation, whereas Wt1 maintains self-renewal by modulating Fgf signals. ${ }^{9,10}$ Furthermore, it has been demonstrated in mice that Bmp7 promotes proliferation of nephron progenitor cells via a Jnk-dependent mechanism involving phosphorylation of Jun and Atf2. ${ }^{19}$

To date, research related to transcriptional regulatory control of mammalian nephrogenesis has been limited to the mouse ${ }^{6,12}$ or to transcriptome "snapshots" in human. ${ }^{20}$ A recent study demonstrated conserved and divergent genes associated with human and mouse kidney organogenesis, ${ }^{21}$ thus further highlighting the need for primary human renal stem cell models to better dissect nephrogenesis at the molecular level. Furthermore, species differences need to be considered, for example, mammalian nephrons arise from a limited nephron progenitor pool through a reiterative inductive process extending over days (mouse) or weeks (human) of kidney development. ${ }^{22}$ Human kidney development initiates around 4 
weeks of gestation and ends around 34-37 weeks of gestation. At the anatomical level, human and mouse kidney development differ in timing, scale, and global features such as lobe formation and progenitor niche organization. ${ }^{21,22,23}$ These are all further evidence in support of the need of a reliable and robust human renal cell culture model.

Expression of pluripotency-associated proteins has enabled rapid reprogramming of urine derived mesenchymal and epithelial cells into induced pluripotent stem cells (iPSCs). ${ }^{24,25,26,27,28}$ Differentiation protocols for generating kidney-associated cell types from human pluripotent stem cells have mimicked normal kidney development. ${ }^{14,29,30,31}$ For example, WNT activation using a GSK3 $\beta$ inhibitor (CHIR99021), FGF9, Activin A, Retinoic acid (RA) and BMP7 as instructive signals have been employed to derive functional podocytes, proximal renal tubules, and glomeruli. ${ }^{15,32,33,34,35,36}$ Despite these efforts and achievements, there will always be variabilities between differentiation protocols, the maturation state of the differentiated renal cells and genes associated with temporal maturation during human kidney organoids formation from human iPSCs. ${ }^{37,38}$ We propose that using native renal stem cells isolated directly from urine will circumvent most of the shortfalls and deficiencies associated with human pluripotent stem cell-based models.

Here we provide for the first time the full characterisation of UdRPCs at the transcriptome, secretome and cellular level, which has led to the identification of a gene regulatory network and associated signalling pathways that maintain their self-renewal. We anticipate that our data will enhance our meagre understanding of the properties of UdRPCs, and enable the generation of renal disease models in vitro and eventually kidney-associated regenerative therapies. 


\section{Concise Methods}

\section{Ethics}

Ethical approval (Number: 5704) was granted by the ethical committee of the medical faculty of Heinrich Heine University, Düsseldorf, Germany.

\section{UdRPCs isolation and culture}

Urine samples were collected from 10 healthy donors with diverse age, gender and ethnicity (Table 1). Isolation and expansion of the UdRPCs followed the previously established protocols. ${ }^{24,28}$ Adult kidney biopsy derived primary human renal epithelial cells (hREPCs) (C12665, Promo Cell) were used as control. Description of the other cell line used in this study and culture condition has been provided in Supplemental Material and Methods.

\section{CYP2D6 genotyping and phenotyping}

CYP2D6 genotyping and phenotyping of five individuals were carried out by CeGat $\mathrm{GmbH}$ Germany using genomic DNA. The CYP2D6 variant assay reveals the pharmacogenetics (PGx) profile of an individual's genotype and phenotype based on tested pharmacogenetics markers. The assay identifies and discriminates individuals with poor, normal, intermediate and ultra-rapid metabolizing activity. ${ }^{39}$

\section{Analysis of cell proliferation}

Cell proliferation were analysed using resazurin metabolic colorimetric assay is described in details in the Supplemental Material and Methods.

\section{Immunophenotyping by flow cytometry}

The analysis of MSC-associated cell surface marker expression of UdRPCs was performed using MSC Phenotyping Kit (Miltenyi) according to the manufacturer's instructions and as described before. ${ }^{40}$ Description of the details methods has been provided in Supplemental Material and Methods.

\section{Albumin endocytosis assay}

Albumin endocytosis assay was performed as described before. ${ }^{41}$ Description of the details methods has been provided in Supplemental Material and Methods.

\section{Differentiation into adipocytes, chondrocytes and osteoblasts}

Differentiation of UdRPCs into adipocytes, chondrocytes and osteoblasts were tested using the StemPro Adipogenesis, Chondrogenesis, and Osteogenesis differentiation Kits (Gibco, 
Life Technologies, CA, USA) as described before. ${ }^{40,41}$ A light microscope was used for imaging. Methods described in details in the Supplemental Material and Methods.

\section{Bisulfite genomic sequencing}

Bisulfite sequencing was performed following bisulfite conversion with the EpiTec Kit (Qiagen, Hilden, Germany). Primers were designed after excluding pseudogenes or other closely related genomic sequences which could interfere with specific amplification by amplicon and primer sequences comparison in BLAT sequence database (https://genome.ucsc.edu/FAQ/FAQblat.html). In brief, the amplification conditions were denaturation at $95^{\circ} \mathrm{C}$ for $13 \mathrm{~min}$. followed by 37 cycles of $95^{\circ} \mathrm{C}$ for $50 \mathrm{~s}$, TM for $45 \mathrm{~s}$ and $72^{\circ} \mathrm{C}$ for 30s. The amplification product is $469 \mathrm{bp}$ in size. Amplification product was cloned into pCR2.1vector using the TA Cloning Kit (Invitrogen, Carlsbad, United States) according to the manufacturer's instructions. On average 30 clones were sequenced using the BigDye Terminator Cycle Sequencing Kit (Applied Biosystems, Foster City, United States) on a DNA analyzer 3700 (Applied Biosystems) with M13 primer to obtain a representative methylation profile the OCT4 promoter region. 5'-regulatory gene sequences are defined by +1 transcription start of the following sequence: Homo sapiens POU class 5 homeobox 1 (POU5F1), transcript variant 1, mRNA. NCBI Reference Sequence: NM_002701.6

\section{Generation of iPSC from UdRPCs}

UdRPCs were reprogrammed into iPSCs using an integration-free episomal based transfection system without pathway inhibition. Briefly, UdRPCs were nucleofected with two plasmids pEP4 E02S ET2K (Addgene plasmid \#20927) and pEP4 E02S CK2M EN2L (Addgene plasmid \#20924) expressing a combination of pluripotency factors including OCT4, SOX2, LIN28, c-MYC, KLF4, and NANOG using the Amaxa 4D-Nucleofector Kit according to the manufacturer's guidelines and as described previously. ${ }^{28}$

\section{Immunofluorescence study and Western blot analysis}

Immunofluorescence study was performed as described previously. ${ }^{40}$ List of primary antibody presents in Supplementary Table S1. Details methods of Immunofluorescence study and Western blot analysis have been described in Supplemental Material and Methods.

\section{Quantitative RT-PCR analysis}

Real-time quantitative PCR was performed in technical triplicates with Power SYBR Green Master Mix (Life Technologies), 12.5 $\square$ ng cDNA per sample and $0.6 \square \mu \mathrm{M}$ primers on a VIIA7 (Life Technologies) machine. Mean values were normalized to levels of the housekeeping 
gene ribosomal protein L37A calculated by the $2-\Delta \Delta \mathrm{Ct}$ method. Primers used were purchased from MWG (primer sequences and predicted sizes of amplicons presented in supplementary table S2).

\section{Culture supernatant analysis}

For the detection of cytokines secreted by the UdRPCs, we employed the Proteome Profiler Human Cytokine Array Panel A (R\&D Systems, MA, USA) following the manufacturer's instructions. Correlation variations and $p$ values were calculated based on the pixel density.

\section{Microarray data analyses}

Total RNA $(1 \mu \mathrm{g})$ preparations were hybridized on the PrimeView Human Gene Expression Array (Affymetrix, Thermo Fisher Scientific) at the core facility Biomedizinisches Forschungszentrum (BMFZ) of the Heinrich Heine University Düsseldorf. Gene expression data will be available online at the National Center of Biotechnology Information (NCBI) Gene Expression Omnibus. The raw data was imported into the R/Bioconductor environment ${ }^{42}$ and further processed with the package affy ${ }^{43}$ using background-correction, logarithmic (base 2) transformation and normalization with the Robust Multi-array Average (RMA) method. The heatmap.2 function from the gplots package ${ }^{44}$ was applied for cluster analysis and to generate heatmaps using Pearson correlation as similarity measure. Gene expression was detected as previously described ${ }^{45}$ using a detection-p-value threshold of 0.05 . Differential gene expression was determined via the $p$-value from the limma package ${ }^{46}$ which was adjusted for false discovery rate using the q value package. ${ }^{47}$ Thresholds of 1.33 and 0.75 were used for up-/down-regulation of ratios and 0.05 for $p$-values. Venn diagrams were generated with the VennDiagram package. ${ }^{48}$ Subsets from the venn diagrams were used for follow-up GO and pathway analyses.

\section{KEGG pathway, GO and network analysis}

Gene ontology (GOs) terms were analysed within the Bioconductor environment employing the package GOstats. ${ }^{49}$ GOs of category Biological Process (BP) were further summarized with the REVIGO tool ${ }^{50}$ to generate treemaps populating the parameter for allowed similarity with tiny=0.4. GO networks were generated from the REVIGO tool in $\mathrm{xgmml}$ format and imported into Cytoscape. ${ }^{51}$ To reduce the network to a readable size they were filtered in Cytoscape by the $\log 10(p)$ between -3.75 and -2.75 . The saturation of the red nodes representing $\mathrm{GO}$ terms indicates the significance via the $p$-value while the grey value of the edges represents their similarity. KEGG pathways ${ }^{52}$ were downloaded from the KEGG 
server in March 2018 and tested for over-representation with the R-built-in hypergeometric test.

\section{Activated WNT pathway associated protein interaction network}

The network was constructed from the 20 most significantly up- and down down-regulated genes between CHIR99021 treatment and untreated controls. Genes were ranked by the limma-p-value and passed the criteria: detection p-value $<0.05$ for the dedicated condition, ratio $<0.75$ or ratio $>1.33$, limma-p-value $<0.05$. The resulting 40 genes are marked as green nodes in the network. Interacting proteins containing at least one protein coded by the 40 genes were retrieved from BioGrid version 3.4.161. ${ }^{53}$ To reduce complexity and increase visualization, the network was minimized by adding only the $n=30$ interacting proteins (marked as red nodes) with the most interactions to proteins coded by the 40 genes. The plot of the interactions network was drawn employing the $\mathrm{R}$ package network. ${ }^{54}$ Communities of related proteins within the network were detected employing an in-betweenness clustering analysis via the method cluster_edge_betweenness () from the R package igraph. ${ }^{55}$

\section{Statistics}

All data are presented as arithmetic means \pm standard error of mean. At least 3 independent experiments were used for the calculation of mean values. Statistical analysis was performed by $U$-test and student's t-test. $P$ values of $<0.05$ were considered significant. 


\section{Results}

UdRPCs express a subset of pluripotent stem cell-associated markers and possess features typical of bone marrow-derived MSC

Urine samples were collected from 10 healthy adult donors (4 males-UM and 6 females-UF) with ages ranging from 21 to 61 years, and of mixed ethnicity ( 3 african and 7 caucasian) (Table 1). Attached cells emerged as isolated clusters after 7 days, thereafter these acquired a "rice grain" fibroblast-like morphology resembling MSCs (Figure 1A). A selection of distinct UdRPC populations $(n=4)$ were used to assay cell proliferation and growth. After 3 days in culture, the cells exited the lag phase and growth began in an exponential phase. Cells attained stationary phase at day 7 of subculture, and entered in a decline phase after 7-9 days (Figure 1B). All four populations- UM27, UM16, UM51 and UF45 showed similar proliferation and growth patterns.

Flow cytometry analysis revealed that approximately $98.9 \%$ of the cells express SSEA4, TRA-1-60 (11.3\%) and TRA-1-81 (16.5\%) (Figure 1C). These data were confirmed by immunofluorescent-based staining which also showed expression of the typical mesenchymal marker- Vimentin and the proliferation-associated stem cell markers- C-KIT and CD133 (Figure 1D). In order to reveal the detailed methylation pattern of the 5'regulatory region of the OCT4 gene in iPSCs derived from the UM51 and the corresponding parental cells (control) we employed standard bisulfite sequencing. In total 330 Cytosinephosphatidyl-Guanine-dinucleotides (CpG) slightly upstream of the transcription starting site (TSS) of the OCT4 gene were analysed. Within this 469bp long region, a dense methylation pattern was observed in the UM51 control cells, with 92.4\% (305) of the CpG dinucleotides identified were methylated. In contrast, iPSCs derived from UM51 had $72.12 \%$ (207) of analysed CpGs were unmethylated (Supplemental Figure S1).

Flow cytometry analysis of critical MSC cell surface markers were negative for the hematopoietic markers CD14, CD20, CD34, and CD45 and positive for CD73, CD90 and CD105 albeit at variable levels (Supplemental Figure Figure S2). Typical of MSCs, UdRPCs can be driven to differentiate into osteocytes, chondrocytes, and adipocytes when cultured in the respective differentiation medium for 3 weeks (Figure 1E). Furthermore, employing a cytokine array $(n=2)$, a repertoire of trophic factors such as IL8, GDF-15, SERPINE-1, Angiogenin, VEGF, and Thrombospondin-1 was detected as secreted in a similar manner as fetal-femur derived MSCs (Figure 1F, Supplemental Figure S2). 
The CYP2D6 genotypes investigated were distinct between groups of individuals, thus reflecting the diverse drug metabolizing activity between individuals. UM51 for example expresses the CYP2D6 ${ }^{*} 4 /{ }^{*} 17$ genotype which confers an intermediate metabolizing activity $^{28}$ whereas UF31 bears the CYP2D6*1/*41 genotype which confers an ultra-rapid metabolizing activity. The other three individuals (UF21, UF45 and UM27) are endowed with normal drug metabolizing rates (Table 1).

UdRPCs express key renal progenitor cell markers and are able to endocytose Albumin

Immunofluorescence-based staining revealed expression of the key proteins including transcription factors associated with kidney development- SIX2, CITED1, WT1, Nephrin, LHX1, and PAX8 as shown by representative pictures (Figure 2A). Additionally they were shown to express Cytokeratin 19 and PODXL (Supplemental Figure S2) and transport Albumin (Figure 2B).

\section{Comparative transcriptome analysis of UdRPCs and kidney biopsy derived hREPCs}

A hierarchical clustering and heatmap analysis was carried out to compare the transcriptomes of UdRPCs with the kidney biopsy-derived renal epithelial proximal cells (hREPCs). As anticipated, all UdRPCs clustered together as a common cell type distinct from hREPCs.

UdRPCs express higher levels of renal progenitor cell markers such as SIX2, CITED1, UMOD, PAX2, NPHS2, GDNF, SALL4, MIXL1 and OSR1. This heatmap also revealed that UdRPCs are of mesenchymal origin expressing VIM and SIX2 whereas the hREPCs are differentiated epithelial expressing $C D H 1$ and elevated levels of GATA3 and SOX17 (Figure $3 A$ ). Direct comparison of logarithmic (base 2) gene expression values of UdRPCs, for instance UM51 with hREPCs, in a scatter plot (Figure 3B) shows similarity with a high Pearson correlation of 0.9575 . The more epithelial character of hREPCs is reflected by CDH1 which has one of the highest ratios between hREPCs and UM51 $r=156.96$. Additionally, an elevated expression of the mesenchymal marker VIM in UM51 $r=1.1$ confirmed the mesenchymal phenotype of UdRPCs. The comparison of expressed genes (det-p < 0.05) in UdRPCs (UM51) and hREPCs in a venn diagram (Figure 3C) showed that most genes are expressed in common (12281), whereas 566 are expressed exclusively in UM51 and 438 exclusively in hREPCs. The 10 most over-represented GO BP terms (biological processes) in the UM51 exclusive gene-set include triglyceride homeostasis, kidney development and urogenital system development, whereas the hREPCs exclusive gene set includes chloride transmembrane transport, anion transport and response to 
lipopolysaccharides (Figure 3D). The common gene set consists of 874 up-regulated genes (ratio > 2) in UM51 (e.g. renal tubule development, urogenital system development and anterior/posterior pattern specification) and 1042 down-regulated genes (ratio < 0.5) in UM51 (e.g. cell division and cholesterol biosynthetic process) (Figure 3E).

\section{Confirmation of the renal origin of UdRPCs and retention of renal-associated genes in UdRPC derived iPSCs}

A venn diagram-based comparison of gene expression (det- $p<0.05$ ) in UdRPCs and human foreskin fibroblasts (HFF) was carried out (Figure 4A) in order to dissect common and distinct gene expression patterns. The majority of genes (11649) are expressed in common, 463 exclusively in UdRPCs and 891 in fibroblasts. The 463 genes were further analysed for overrepresented GOs and summarized as a GO network (Figure 4B) with the tools REVIGO, and Cytoscape was used for the GO terms of the category BP. In addition to several developmental terms such as organ induction, regulation of embryonic development (high number of edges referring to similarity to many terms), specific renal-related terms including urogenital system development, mesenchymal cell proliferation involved in ureteric bud development and positive regulation of nephron tubule epithelial cell differentiation (marked with blue ellipse, intense red indicating higher significance) were identified. Interestingly, the non-canonical Wnt signalling pathway, which plays a major role in kidney development, is also over-represented (orange ring-top left).

The dendrogram based on the global transcriptome analysis revealed a clear separation of UdRPCs lines $(n=9)$ from the differentiated UdRPCs (CHIR 99021 treated UdRPCs, $n=3$ ), UdRPCs-iPSCs ( $n=4)$ and embryonic stem cells (H1 and H9) (Figure 4C). Characterization of the derived UdRPC-iPSCs is depicted in Supplemental Figure S2 (Supplemental Figure S3A, S3B, S3C, and S3D). In the venn diagram (Figure 4D) we compared expressed genes (det-p $<0.05$ ) in UdRPC-iPSCs with ESCs and HFF-iPSCs. Most genes (12092) are expressed in common in all cell types while 150 genes are expressed exclusively in UdRPC-iPSCs. The genes expressed exclusively in one cell type were further analysed for over-representation of GO terms. The treemap summarizing the GO terms of category BP over-represented in the 150 genes expressed exclusively in UdRPC-iPSCs (Figure 4E) indicates that UdRPC-iPSCs retain a memory of their kidney origin. In addition to the largest most significant grouppositive regulation of urine volume, it consists of other renal-related GO terms (e.g. calcium transport, vitamin D). Stem-cell-related and developmental terms such as positive regulation of cell proliferation are due to their pluripotent nature. Within the treemap summarizing the GO-BP terms over-represented in the 312 genes expressed exclusively in HFF-iPSCs, the 
largest most significant group is associated with negative regulation of myoblast differentiation, thus pointing at the fibroblast origin of these iPSCs (Figure 4E). Furthermore, within the treemap summarizing the GO-BP terms over-represented in the 197 genes expressed exclusively in ESCs, the largest most significant group is associated with negative regulation of astrocyte differentiation- hinting at their known propensity to differentiate into the ectodermal lineage (Supplemental Figure S4).

\section{WNT pathway activation by GSK3 $\beta$ inhibition induces differentiation of UdRPCs into renal epithelial proximal tubular cells}

To differentiate 3 independent UdRPC preparations, the cells were treated with $10 \mu \mathrm{M}$ CHIR99021 (WNT pathway activation by GSK3 $\beta$ inhibition) for 2 days and morphological changes from fibroblastic to elongated tubular shape were observed (Figure 5A). In the venn diagram, expressed genes (det-p < 0.05) in untreated UdRPCs are compared to UdRPCs treated with CHIR99021. Genes expressed in common amounts to 11790, of these 2491 are upregulated in the CHIR99021 treatment $(p<0.05$, ratio $>1.33)$ and 2043 are downregulated $(p<0.05$, ratio $<0.75$ ) (Figure 5B, Supplemental Table S6). Among the upregulated genes, 27 are considered "novel" (gene symbol starting with "LOC"), 21 among the down-regulated genes and 98 among the non-regulated genes (Supplemental Table S6). The heatmap based on the top 20 regulated genes shows a clear separation between untreated and treated cells (Figure 5C). Amongst the up-regulated genes, the associated KEGG pathways include WNT-signaling (AXIN2, JUN, NKD1) (Supplemental Figure S5). Over-representation analysis of the up-regulated genes and their associated KEGG pathways identified protein processing in endoplasmic reticulum as highly significant and several signalling pathways such as mTOR, Insulin, p53, AMPK and TNF. Overrepresentation analysis of the down-regulated genes and associated KEGG pathways revealed cell cycle, cellular senescence, focal adhesion, FoxO, ErbB and thyroid hormone signalling. Interestingly Hippo pathway was regulated in both undifferentiated and differentiated UdRPCs (Figure 5D).

\section{Regulation of self-renewal and differentiation in UdRPCs}

Further to the transcriptome analyses (Figure 5), Real-time PCR revealed downregulation of the stem cell self-renewal associated gene CD133 and activated expression of the nephrogenesis-associated gene BMP7 after CHIR stimulation (Figure 6A).

To identify key self-renewal regulators and pathways in UdRPCs, a protein-proteininteraction network was generated. The network of the 40 proteins, encoded by the 20 most 
significantly up- and down-regulated genes between CHIR treated and untreated UdRPCs (Figure $5 \mathrm{C}$ ) indentified JUN as a major hub - in terms of having most connections to other proteins in the network. However, in the WNT-signaling pathway JUN is at the end of a downstream cascade from GSK3B, including further downstream targets- AXIN2 and CTNNB1. The genes encoding these proteins were differentially regulated by the CHIR treatment (green nodes) (Figure 6B). Several communities with more interactions within the community than to other communities can be detected in the network via community clustering of the network via edge-betweenness includes JUN (red), GSK3B / AXIN2 / CTNNB1 (green), LATS2 (yellow), EGFR (pink) (Figure 6C). To analyze the effect of WNT activation on the TGF $\beta$-SMAD pathway, Western blot analysis was performed to detect phosphorylation levels of SMAD 2/3 and SMAD 1/5/8 in UF45, UM51 and UM27. In the differentiated cells (UdRPCs after CHIR treatment) a decreased level of phosphorylated SMAD 2/3 and increased levels of phosphorylated SMAD 1/5/8 were observed (Figure 6D). 


\section{Discussion}

Here we describe urine as a reliable, robust and cheap source of renal stem cells, in contrast to amniotic fluid or kidney biopsies. ${ }^{41,56}$ Urine can be accessed non-invasively, without risk for the patient and repeated samples can be collected from the same donor over prolonged periods. Urine derived stem cells can be expand from a single clone with high proliferation potency. ${ }^{24,57}$ We propose naming these cells as urine derived renal progenitor cellsUdRPCs, because they can be kept in culture for almost 12 passages whilst maintaining expression of the self-renewal associated proteins- CD133, C-KIT, TRA-1-60, TRA-1-81 and SSEA4 (Figure 1D) as has been shown by others ${ }^{24,41}$ Despite the expression of these pluripotency-associated factors, UdRPCs do not express OCT4, SOX2 and NANOG- which are key pluripotency-regulating transcription factors. ${ }^{58,59}$ Further evidence in support of the lack of OCT4 expression is our observed OCT4 promoter methylation pattern in the UM51 cells, with $92.4 \%$ (305) of the CpG dinucleotides identified as methylated whereas iPSCs derived from UM51 had $72.12 \%$ (207) of analysed CpGs unmethylated (Supplemental Figure S1).

UdRPCs express key renal progenitor-regulatory proteins SIX2, CITED1, WT1 and NPHS1 (Figure 2A) indicating they originate from the kidney as described from others. ${ }^{13,56,60}$ Furthermore, UdRPCs transport Albumin (Figure 2B) as observed in renal stem cells. ${ }^{41,61} \mathrm{We}$ have shown that UdRPCs are in fact bon-fide MSCs- i.e. they express VIM and not CDH1, adhere to plastic surfaces, express CD73, CD90 and CD105 and not the hematopoietic markers CD14, CD20, CD34, and CD45 (Supplemental Figure S2). Typical of MSCs, UdRPCs can be differentiated into osteoblasts, chondrocytes and adipocytes (Figure 1E). ${ }^{41,56,62}$ They also secrete a plethora of cytokines and growth factors- such as EGF, GDF, PDGF and Serpin E1 (Figure 1F). ${ }^{63}$

With regards to nephrogenesis-associated regulatory genes, ${ }^{17,30}$ we observed SIX2, CITED1, GDNF, WT1, NPHS1, PAX2 expression in UdRPCs but at variable expression levels between individual cell preparations (Figure 3A). The GOs network derived from the exclusively expressed genes in UdRPCs (compared to HFF) unveiled renal system development- related terms (Figure 4B). Furthermore, the GOs from the UdRPCs-iPSC exclusive genes set, in contrast to pluripotent stem cells, identified terms related to renal function therefore implying the preservation of their kidney origin (Figure 4E). As the conservation of tissue of origin in iPSCs might be linked to epigenetic memory, ${ }^{4,64}$ UdRPCs as well as UdRPCs-iPSCs, especially with known CYP2D6 status, might be advantageous for differentiation into renal cells, modelling kidney-related diseases, nephrotoxicity studies 
and regenerative medicine. However, dissecting the gene regulatory mechanisms that drive human renal progenitor growth and differentiation in vitro represents the key step for translation but remains a challenge due to the absence of well-characterised urine derived stem cells. Here we have shown that UdRPCs are a self-renewing stem cell population unlike the kidney biopsy-derived hREPCs which are differentiated renal epithelial cells (Figure 3A, Figure 3B). To demonstrate that UdRPCs can maintain self-renewal when cultured under undifferentiation conditions but yet retain the potential for epithelial differentiation and nephrogenesis, we induced active WNT signalling, by treatment with the GSK-3 $\beta$ inhibitor- CHIR99021. The differentiated cells adopted an elongated tubular morphology (Figure 5A) and reduced proliferation as also shown for human ESC and iPSC derived renal epithelial cells. ${ }^{65,66,67}$

Although WNT pathway activation induced an epithelial phenotype, we did not see a dramatic increase in $\mathrm{CDH} 1$ expression but rather activation of $\mathrm{CDH}-3$ expression (8.86 fold) (Supplemental Table S6). Cdh-3, a gene encoding a member of the cadherin superfamily, functions in epithelial cell morphogenesis in Caenorhabditis elegans ${ }^{68}$ an event which is poorly understood in human nephrogenesis.

In line with our previously published observations in amniotic fluidic-derived renal cells, the down-regulated expression of SIX2,WT1, CD133 and upregulated expression of BMP7 (Figure 6A) induced the loss of self-renewal. ${ }^{41}$ Global transcriptome analyses also revealed the down-regulation of 2043 genes some of which are associated with pathways such as cell cycle, FoxO, Hippo and ErbB signalling (Figure 5D). The Hippo pathway which is composed of WNT target genes such as LATS2, AXIN2 and CTNNB1 have been reported to regulate epithelialization of nephron progenitors. ${ }^{69,70}$

We detected differential expression 40 genes in which 20 most significantly up- and downregulated between WNT-induced differentiated and self-renewing UdRPCs (Figure 5C). Amongst the genes up regulated in the CHIR treated cells are the WNT targets- AXIN2, JUN and NKD1 known to be associated with WNT signalling (Supplemental Figure S5). Interestingly, a protein interaction network identified JUN as a major hub connected to GSK3 $\beta$ and interlinked with ATF2, STAT3, GATA2 and MAPK1 (Figure 6B, Figure 6C). Interestingly, in a mouse nephrogenesis model, Bmp7 phosphorylates Jun and Atf2 via Jnk signalling which promote the proliferation of mouse nephron progenitors. ${ }^{19}$ This indeed might be contradictory to our observed elevated expression of BMP7 upon WNT induced differentiation of UdRPCs- i.e. suppression of BMP7 expression is needed to maintain selfrenewal in UdRPCs. It is well known that TGF $\beta$ signals through pSMAD2/3 whereas BMPs 
activate SMAD1/5/8. Since, SMADs are a target of MAPK particularly of JNK, BMPs and TGF $\beta$ both can activate the SMAD circuit. ${ }^{71,72}$

Based on this study and our previously published data in human amniotic fluid-derived renal cells, ${ }^{41}$ we propose that similar to self-renewal in human pluripotent stem cells, UdRPCs maintain self-renewal by active FGF signalling leading to phosphorylated TGF $\beta$ - SMAD2/3 (Figure $6 D$ ). ${ }^{59,73}$ In contrast, activation of WNT/ $\beta$-catenin signalling leads to an upregulation of JUN and BMP7 leading to activation of SMAD1/5/8 signalling (Figure 6D) and exit of selfrenewal by downregulation of $W T 1, S I X 2, C I T E D 1$, and CD133 expression. To surmise, we derived a hypothetic scheme of the WNT $\beta$ catenin and TGF $\beta$ pathway-mediated cell fate decisions in UdRPCs. This simplistic model is depicted in Figure 7.

Comparing self-renewal of renal progenitor cells in both human (UdRPCs) and mouse, it is clear that an intricate balance is needed between SIX2, WT1, CITED1 expression and Wnt/ $\beta$-catenin activity in order to determine the cell fate of nephron progenitor cells. ${ }^{7,11,17,21}$ Furthermore, it remains to be determined if indeed there exist subtle human and mouse differences in the gene regulatory network needed to maintain a self-renewing renal progenitor pool in both species and we believe that human UdRPCs as described here will facilitate these studies. 


\section{Data access}

All raw and processed data used in this study have been archived in NCBI gene expression omnibus under GEO accession number GSE128281.

(https://www.ncbi.nlm.nih.gov/geo/query/acc.cgi?acc=GSE128281).

\section{Author contributions}

Conception: J. A and M.B; Cell culture experiments: M.S.R, L.S.S, F.A, M.B and J.A; Real Time PCR: F.A; Bisulphite sequencing: L.E; Bioinformatics: W.W and J.A; Proliferation assays and Western blot analyses: S.M; Derivation and characterisation of iPSCs: M.B, N.G and A.N; FACS analysis: M.B; Writing of manuscript: M.S.R, W.W, L.S.S and J.A; Final edits: J.A; and all authors approved the final version of the manuscript.

\section{Acknowledgements}

James Adjaye acknowledges support from the medical faculty of the Heinrich Heine University- Düsseldorf, Germany. Md Shaifur Rahman acknowledges support from the German Academic Exchange Service (DAAD-91607303).

\section{Disclosure of financial interests}

None 


\section{References}

1. Ringsrud KM: Casts in the Urine Sediment. Laboratory Medicine 32: 191-193, 2001.

2. Benedetta B, Stefania B, Cristina G, Stefano B, Chiara DM, Dario C, Giovanni C: Isolation of renal progenitor cells from adult human kidney. The American journal of pathology 166: 545-555, 2005.

3. Sagrinati C, Netti GS, Mazzinghi B, Lazzeri E, Liotta F, Frosali F, Ronconi E, Meini C, Gacci M, Squecco R, et al: Isolation and characterization of multipotent progenitor cells from the Bowman's capsule of adult human kidneys. J Am Soc Nephrol 17: 2443-2456, 2006.

4. Manaph NPA, Al-Hawwas M, Bobrovskaya L, Coates PT, Zhou XF: Urine-derived cells for human cell therapy. Stem Cell Res Ther 9: 189, 2018.

5. Bharadwaj S, Liu G, Shi Y, Wu R, Yang B, He T, Fan Y, Lu X, Zhou X, Liu H, et al: Multipotential differentiation of human urine-derived stem cells: Potential for therapeutic applications in urology. Stem Cells 31: 1840-1856, 2013.

6. O'Brien LL, Guo Q, Bahrami-Samani E, Park JS, Hasso SM, Lee YJ, Fang A, Kim AD, Guo J, Hong TM, Peterson KA, Lozanoff S, Raviram R, Ren B, Fogelgren B, Smith AD, Valouev A, McMahon AP: Transcriptional regulatory control of mammalian nephron progenitors revealed by multi-factor cistromic analysis and genetic studies. PLoS Genet 14: e1007181, 2018.

7. Ramalingam H, Fessler AR, Das A, Valerius MT, Basta J, Robbins L, Brown AC, Oxburgh L, McMahon AP, Rauchman M, Carroll TJ: Disparate levels of beta-catenin activity determine nephron progenitor cell fate. Dev Biol 440:13-21, 2018.

8. Xu J, Liu H, Park JS, Lan Y, Jiang R: Osr1 acts downstream of and interacts synergistically with Six2 to maintain nephron progenitor cells during kidney organogenesis. Development 141:1442-1452, 2014.

9. Kann M, Bae E, Lenz MO, Li L, Trannguyen B, Schumacher VA, Taglienti ME, Bordeianou L, Hartwig S, Rinschen MM, et al: WT1 targets Gas1 to maintain nephron progenitor cells by modulating FGF signals. Development 142: 1254-1266, 2015.

10. Motamedi FJ, Badro DA1, Clarkson M, Lecca MR, Bradford ST, Buske FA, Saar K, Hübner N, Brändli AW, Schedl A: WT1 controls antagonistic FGF and BMP-pSMAD pathways in early renal progenitors. Nat Commun 5: 01-14, 2014.

11. Park JS, Ma W, O'Brien LL, Chung E, Guo JJ, Cheng JG, Valerius MT, McMahon JA, Wong WH, McMahon AP: Six2 and Wnt regulate self-renewal and commitment of nephron progenitors through shared gene regulatory networks. Dev Cell 23: 637-651, 2012.

12. Lawlor KT, Zappia L, Lefevre J, Park JS, Hamilton NA, Oshlack A, Little MH, Combes AN: Nephron progenitor commitment is a stochastic process influenced by cell migration. Elife 8pii: e41156, 2019.

13. Murphy AJ, Pierce J, de Caestecker C, Taylor C, Anderson JR, Perantoni AO, de Caestecker MP, Lovvorn HN: SIX2 and CITED1, markers of nephronic progenitor selfrenewal, remain active in primitive elements of Wilms' tumor. J Pediatr Surg 47: 1239-1249, 2012. 
14. Kobayashi A, Mugford JW, Krautzberger AM, Naiman N, Liao J, McMahon AP: Identification of a multipotent self-renewing stromal progenitor population during mammalian kidney organogenesis. Stem Cell Reports 3: 650-662, 2014.

15. Little MH, Kairath P: Does Renal Repair Recapitulate Kidney Development? J Am Soc Nephrol 28: 34-46, 2017.

16. James RG, Kamei CN, Wang $Q$, Jiang R, Schultheiss TM: Odd-skipped related 1 is required for development of the metanephric kidney and regulates formation and differentiation of kidney precursor cells. Development 133: 2995-3004, 2006.

17. Kobayashi A, Valerius MT, Mugford JW, Carroll TJ, Self M, Oliver G, McMahon AP: Six2 defines and regulates a multipotent self-renewing nephron progenitor population throughout mammalian kidney development. Cell Stem Cell 3: 169-181, 2008.

18. Self M, Lagutin OV, Bowling B, Hendrix J, Cai Y, Dressler GR, Oliver G: Six2 is required for suppression of nephrogenesis and progenitor renewal in the developing kidney. EMBO $J$ 25: 5214-5228, 2006.

19. Blank U, Brown A, Adams DC, Karolak MJ, Oxburgh L: BMP7 promotes proliferation of nephron progenitor cells via a JNK-dependent mechanism. Development 136: 3557-3566, 2009.

20. Da Sacco S, Thornton ME, Petrosyan A, Lavarreda-Pearce M, Sedrakyan S, Grubbs $\mathrm{BH}$, De Filippo RE, Perin L: Direct Isolation and Characterization of Human Nephron Progenitors. Stem Cells Transl Med 6: 419-433, 2017.

21. Lindström NO, McMahon JA, Guo J, Tran T, Guo Q, Rutledge E, Parvez RK, Saribekyan G, Schuler RE, Liao C, et al: Conserved and Divergent Features of Human and Mouse Kidney Organogenesis. J Am Soc Nephrol 3: 785-805, 2018a.

22. Lindström NO, De Sena Brandine G, Tran T, Ransick A, Suh G, Guo J, Kim AD, Parvez RK, Ruffins SW, Rutledge EA, et al: Progressive Recruitment of Mesenchymal Progenitors Reveals a Time-Dependent Process of Cell Fate Acquisition in Mouse and Human Nephrogenesis. Dev Cell 45: 651-660, 2018b.

23. Thiagarajan RD, Georgas KM, Rumballe BA, Lesieur E, Chiu HS, Taylor D, Tang DT, Grimmond SM, Little MH: Identification of anchor genes during kidney development defines ontological relationships, molecular sub-compartments and regulatory pathways. PLoS One 6: e17286, 2011.

24. Zhou T, Benda C, Duzinger S, Huang Y, Li X, Li Y, Guo X, Cao G, Chen S, Hao L, et al: Generation of induced pluripotent stem cells from urine, J Am Soc Nephrol 22: 1221-1228, 2011.

25. Zhou T, Benda C, Dunzinger S, Huang Y, Ho JC, Yang J, Wang Y, Zhang Y, Zhuang Q, $\mathrm{Li}$ Y: Generation of human induced pluripotent stem cells from urine samples. Nat Protoc 7: 2080-2089, 2012.

26. Uhm KO, Jo EH, Go GY, Kim SJ, Choi HY, Im YS, Ha HY, Jung JW, Koo SK: Generation of human induced pluripotent stem cells from urinary cells of a healthy donor using a nonintegration system. Stem Cell Res 21: 44-46, 2017. 
27. Sauer V, Tchaikovskaya T, Wang X, Li Y, Zhang W, Tar K, Polgar Z, Ding J, Guha C, Fox IJ, et al: Human Urinary Epithelial Cells as a Source of Engraftable Hepatocyte-Like Cells Using Stem Cell Technology. Cell Transplant 25: 2221-2243, 2016.

28. Bohndorf M, Ncube A, Spitzhorn LS, Enczmann J, Wruck W, Adjaye J: Derivation and characterization of integration-free iPSC line ISRM-UM51 derived from SIX2-positive renal cells isolated from urine of an African male expressing the CYP2D $6{ }^{*} 4 /{ }^{*} 17$ variant which confers intermediate drug metabolizing activity. Stem Cell Res 25: 18-21, 2017.

29. Little $\mathrm{MH}$, Combes $\mathrm{AN}$, Takasato M: Understanding kidney morphogenesis to guide renal tissue regeneration. Nat Rev Nephrol 12: 624-635, 2016.

30. Chuah JKC, Zink D: Stem cell-derived kidney cells and organoids: Recent breakthroughs and emerging applications. Biotechnol Adv 35: 150-167, 2017.

31. van den Berg CW, Ritsma L, Avramut MC, Wiersma LE, van den Berg BM, Leuning DG, Lievers E, Koning M, Vanslambrouck JM, Koster AJ, et al: Renal Subcapsular Transplantation of PSC-Derived Kidney Organoids Induces Neo-vasculogenesis and Significant Glomerular and Tubular Maturation In Vivo. Stem Cell Reports 10: 751-765, 2018.

32. Rauch C, Feifel E, Kern G, Murphy C, Meier F, Parson W, Beilmann M, Jennings P, Gstraunthaler G, Wilmes A: Differentiation of human iPSCs into functional podocytes. PLoS One 13: e0203869, 2018.

33. Tanigawa S, Taguchi A, Sharma N, Perantoni AO, Nishinakamura R: Selective In Vitro Propagation of Nephron Progenitors Derived from Embryos and Pluripotent Stem Cells. Cell Rep 15: 801-813, 2016.

34. Morizane R, Lam AQ, Freedman BS, Kishi S, Valerius MT, Bonventre JV: Nephron organoids derived from human pluripotent stem cells model kidney development and injury. Nat Biotechnol 33: 1193-1200, 2015.

35. Morizane R, Bonventre JV: Generation of nephron progenitor cells and kidney organoids from human pluripotent stem cells. Nat Protoc 12: 195-207, 2017.

36. Hariharan K, Reinke P, Kurtz A: Generating Multiple Kidney Progenitors and Cell Types from Human Pluripotent Stem Cells. Methods Mol Biol 1926: 103-115, 2019.

37. Phipson B, Er PX, Combes AN, Forbes TA, Howden SE, Zappia L, Yen HJ, Lawlor KT, Hale LJ, Sun J, et al: Evaluation of variability in human kidney organoids. Nat Methods 16: 79-87, 2019.

38. Wu H, Uchimura K, Donnelly EL, Kirita Y, Morris SA, Humphreys BD: Comparative Analysis and Refinement of Human PSC-Derived Kidney Organoid Differentiation with Single-Cell Transcriptomics. Cell Stem Cell 23: 869-881, 2018.

39. Pinto N, Dolan ME: Clinically relevant genetic variations in drug metabolizing enzymes. Curr Drug Metab 12: 487-97, 2011.

40. Spitzhorn LS, Rahman MS, Schwindt L, Ho HT, Wruck W, Bohndorf M, Wehrmeyer S, Ncube A, Beyer I, Hagenbeck C, et al: Isolation and Molecular Characterization of Amniotic Fluid-Derived Mesenchymal Stem Cells Obtained from Caesarean Sections. Stem Cells Int 2017: 5932706, 2017. 
41. Rahman MS, Spitzhorn LS, Wruck W, Hagenbeck C, Balan P, Graffmann N, Bohndorf M, Ncube A, Guillot PV, Fehm T, Adjaye J: The presence of human mesenchymal stem cells of renal origin in amniotic fluid increases with gestational time. Stem Cell Res Ther 9: 113, 2018.

42. Gentleman RC, Carey VJ, Bates DM, Bolstad B, Dettling M, Dudoit S, Ellis B, Gautier L, Ge Y, Gentry J, et al: Bioconductor: open software development for computational biology and bioinformatics. Genome Biol 5: R80, 2004.

43. Gautier L, Cope L, Bolstad BM, Irizarry RA: affy--analysis of Affymetrix GeneChip data at the probe level. Bioinforma Oxf Engl 20: 307-315, 2004.

44. Warnes GR, Bolker B, Bonebakker L, Gentleman R, Liaw WHA, Lumley T, Maechler M, Magnusson A, Moeller S, Schwartz M, et al: gplots: Various R Programming Tools for Plotting Data. http://CRAN.R-project.org/package=gplots, 2015.

45. Graffmann N, Ring S, Kawala M-A, Wruck W, Ncube A, Trompeter H-I, Adjaye J: Modeling Nonalcoholic Fatty Liver Disease with Human Pluripotent Stem Cell-Derived Immature Hepatocyte-Like Cells Reveals Activation of PLIN2 and Confirms Regulatory Functions of Peroxisome Proliferator-Activated Receptor Alpha. Stem Cells Dev 25: 11191133, 2016.

46. Smyth GK: Linear Models and Empirical Bayes Methods for Assessing Differential Expression in Microarray Experiments. Stat Appl Genet Mol Biol 3. http://www.bepress.com/sagmb/vol3/iss1/art3 (Accessed October 28, 2011), 2004.

47. Storey JD: A direct approach to false discovery rates. J R Stat Soc Ser B Stat Methodol 64: 479-498, 2002.

48. Chen $\mathrm{H}$, Boutros PC: VennDiagram: a package for the generation of highly-customizable Venn and Euler diagrams in R. BMC Bioinformatics 12: 35, 2011.

49. Falcon S, Gentleman R: Using GOstats to test gene lists for GO term association. Bioinforma Oxf Engl 23: 257-258, 2007.

50. Supek F, Bošnjak M, Škunca N, Šmuc T: REVIGO Summarizes and Visualizes Long Lists of Gene Ontology Terms ed. C. Gibas. PLoS ONE 6: e21800, 2011.

51. Shannon P, Markiel A, Ozier O, Baliga NS, Wang JT, Ramage D, Amin N, Schwikowski B, Ideker T: Cytoscape: A Software Environment for Integrated Models of Biomolecular Interaction Networks. Genome Res 13: 2498-2504, 2003.

52. Kanehisa M, Furumichi M, Tanabe M, Sato Y, Morishima K: KEGG: new perspectives on genomes, pathways, diseases and drugs. Nucleic Acids Res 45: D353-D361, 2017.

53. Chatr-Aryamontri A, Oughtred R, Boucher L, Rust J, Chang C, Kolas NK, O'Donnell L, Oster S, Theesfeld C, Sellam A, et al: The BioGRID interaction database: 2017 update. Nucleic Acids Res 45: 369-379, 2017.

54. Butts C: network: A Package for Managing Relational Data in R. Journal of Statistical Software 24: 01-36, 2008.

55. Csardi G, Nepusz T: The igraph software package for complex network research. Inter Journal Complex Systems 1695, 2006. 
56. Arcolino FO, Zia S, Held K, Papadimitriou E, Theunis K, Bussolati B, Raaijmakers A, Allegaert K, Voet T, Deprest J, et al: Urine of Preterm Neonates as a Novel Source of Kidney Progenitor Cells. J Am Soc Nephrol 27: 2762-2770, 2016.

57. Romagnani $P$, Giglio S, Angelotti ML, Provenzano A, Becherucci F, Mazzinghi B, Müller S, Amann K, Weidenbusch M, Romoli S, Lazzeri E, Anders HJ: Next generation sequencing and functional analysis of patient urine renal progenitor-derived podocytes to unravel the diagnosis underlying refractory lupus nephritis. Nephrol Dial Transplant 31: 1541-1545, 2016.

58. Babaie Y, Herwig R, Greber B, Brink TC, Wruck W, Groth D, Lehrach H, Burdon T, Adjaye J. Analysis of Oct4-dependent transcriptional networks regulating self-renewal and pluripotency in human embryonic stem cells. Stem Cells 25:500-510, 2007.

59. Greber B, Lehrach $\mathrm{H}$, Adjaye J: Silencing of core transcription factors in human EC cells highlights the importance of autocrine FGF signaling for self-renewal. BMC Dev Biol 7: 46, 2007b.

60. Combes AN, Wilson S, Phipson B, Binnie BB, Ju A, Lawlor KT, Cebrian C, Walton SL, Smyth IM, Moritz KM, et al: Haploinsufficiency for the Six2 gene increases nephron progenitor proliferation promoting branching and nephron number. Kidney Int 93: 589-598, 2018.

61. Tojo A, Kinugasa S: Mechanisms of glomerular albumin filtration and tubular reabsorption. Int J Nephrol 2012: 481-520, 2012.

62. Dominici M, Le Blanc K, Mueller I, Slaper-Cortenbach I, Marini F, Krause D, Deans R, Keating A, Prockop Dj, Horwitz E: Minimal criteria for defining multipotent mesenchymal stromal cells. The International Society for Cellular Therapy position statement. Cytotherapy 8: 315-317, 2006.

63. Zhang D, Wei G, Li P, Zhou X, Zhang Y: Urine-derived stem cells: A novel and versatile progenitor source for cell-based therapy and regenerative medicine. Genes Dis 1: 08-17, 2014.

64. Kim K, Doi A, Wen B, Ng K, Zhao R, Cahan P, Kim J, Aryee MJ, Ji H, Ehrlich LI, et al : Epigenetic memory in induced pluripotent stem cells. Nature 467: 285-290, 2010.

65. Takasato M, Er PX, Becroft M, Vanslambrouck JM, Stanley EG, Elefanty AG, Little MH: Directing human embryonic stem cell differentiation towards a renal lineage generates a selforganizing kidney. Nat Cell Biol 16: 118-126, 2014.

66. Takasato M, Er PX, Chiu HS, Maier B, Baillie GJ, Ferguson C, Parton RG, Wolvetang EJ, Roost MS, Chuva de Sousa Lopes SM, Little MH: Kidney organoids from human iPS cells contain multiple lineages and model human nephrogenesis. Nature 526: 564-568, 2015.

67. Brown AC, Muthukrishnan SD, Oxburgh L: A synthetic niche for nephron progenitor cells. Dev Cell 34: 229-241, 2015.

68. Pettitt J, Wood WB, Plasterk RH: cdh-3, a gene encoding a member of the cadherin superfamily, functions in epithelial cell morphogenesis in Caenorhabditis elegans. Development 122: 4149-4157, 1996. 
69. Reginensi A, Enderle L, Gregorieff A, Johnson RL, Wrana JL, McNeill H: A critical role for NF2 and the Hippo pathway in branching morphogenesis. Nat Commun 7: 12309, 2016.

70. McNeill H, Reginensi A: Lats1/2 Regulate Yap/Taz to Control Nephron Progenitor Epithelialization and Inhibit Myofibroblast Formation. J Am Soc Nephrol 28: 852-861, 2017.

71. Derynck R, Zhang YE: Smad-dependent and Smad-independent pathways in TGF-beta family signalling. Nature 425: 577-584, 2003.

72. Yamaguchi K, Shirakabe K, Shibuya H, Irie K, Oishi I, Ueno N, Taniguchi T, Nishida E, Matsumoto K: Identification of a member of the MAPKKK family as a potential mediator of TGF-beta signal transduction. Science 270: 2008-2011, 1995.

73. Greber B, Lehrach H, Adjaye J: Fibroblast growth factor 2 modulates transforming growth factor beta signaling in mouse embryonic fibroblasts and human ESCs (hESCs) to support hESC self-renewal. Stem Cells 25: 455-464, 2007a. 
bioRxiv preprint doi: https://doi.org/10.1101/602417; this version posted April 8, 2019. The copyright holder for this preprint (which was not certified by peer review) is the author/funder. All rights reserved. No reuse allowed without permission.

\section{Tables}

Table 1. UdRPCs sample overview

\begin{tabular}{|c|c|c|c|c|c|c|}
\hline Sample ID & Gender & Age & Ethnicity & iPSC & CYP2D6 Genotype & CYP2D6 Phenotype \\
\hline UM48 & M & 48 & African & NO & - & - \\
\hline UF60 & $\mathrm{F}$ & 60 & Caucasian & NO & - & - \\
\hline UM27 & M & 27 & Caucasian & NO & CYP2D $6 * 1 \times 2 / * 4$ & Normal metabolizer (NM) \\
\hline UF27 & $\mathrm{F}$ & 27 & Caucasian & NO & - & - \\
\hline UF61 & $\mathrm{F}$ & 61 & Caucasian & NO & - & - \\
\hline UM51 & M & 51 & African & YES & CYP2D6* $4 /{ }^{*} 17$ & Intermediate metabolizer (IM) \\
\hline UF45 & $\mathrm{F}$ & 45 & Caucasian & YES & CYP2D $6 * 1 / * 4$ & Normal metabolizer (NM) \\
\hline UF31 & $\mathrm{F}$ & 31 & African & YES & CYP2D $6 * 1 / * 41$ & Ultra metabolizer (UM) \\
\hline UF21 & $\mathrm{F}$ & 21 & Caucasian & YES & CYP2D6*2/*2 & Normal metabolizer (NM) \\
\hline UM54 & M & 54 & Caucasian & NO & - & - \\
\hline
\end{tabular}




\section{Figure 1}

A

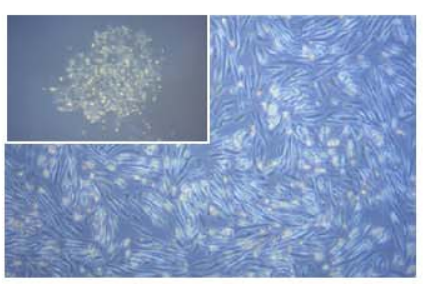

C
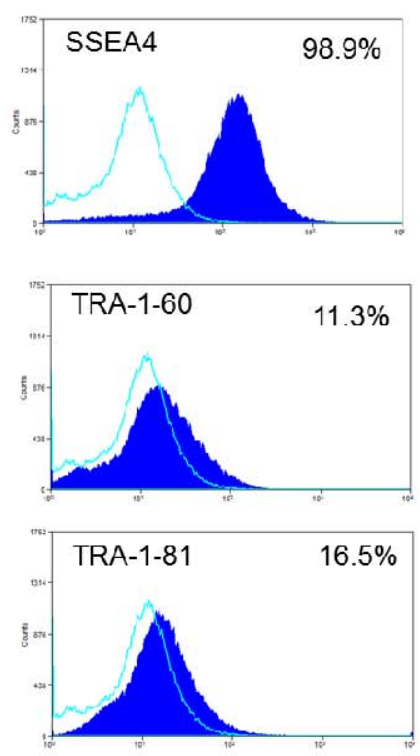

$E$

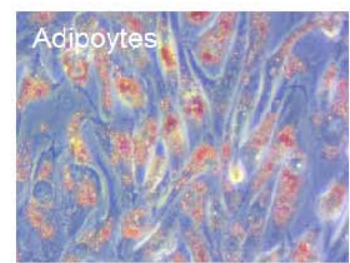

B

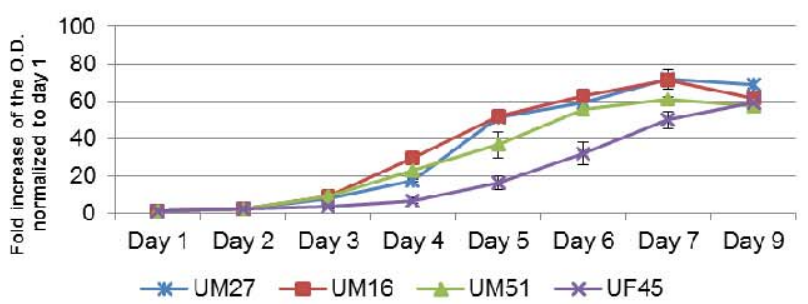

D
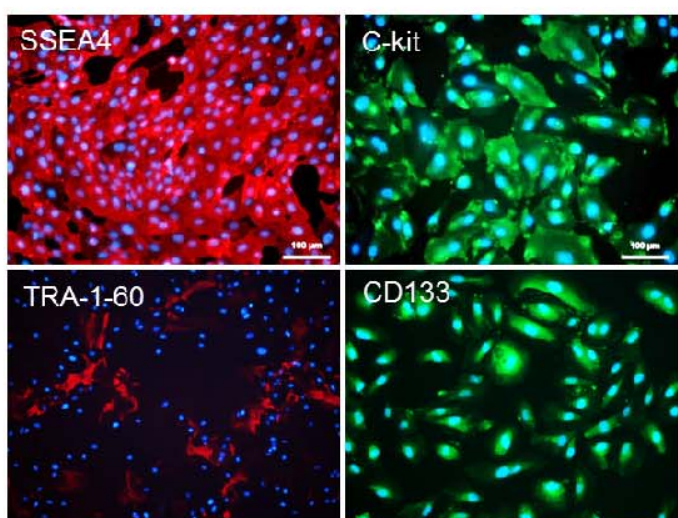

TRA-1-81
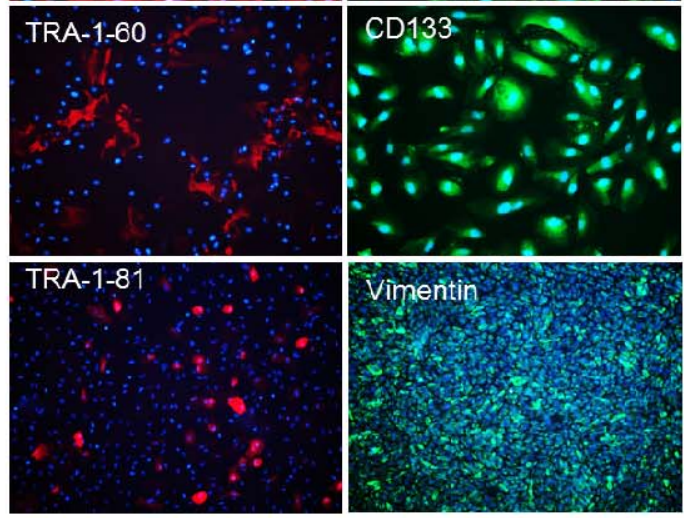

F

Chondrocytes
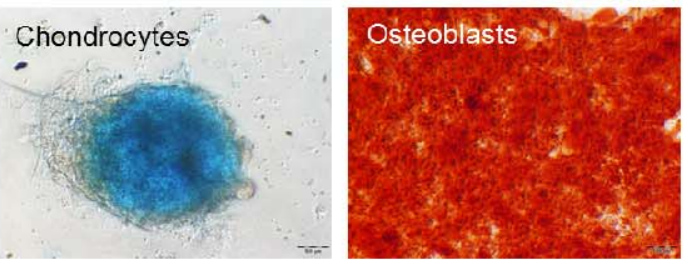

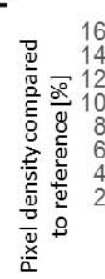
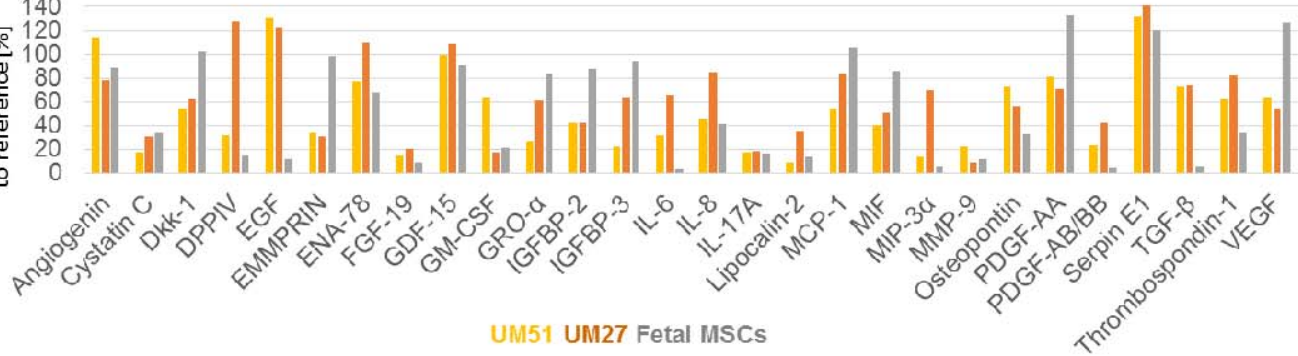


\section{Figure 2}
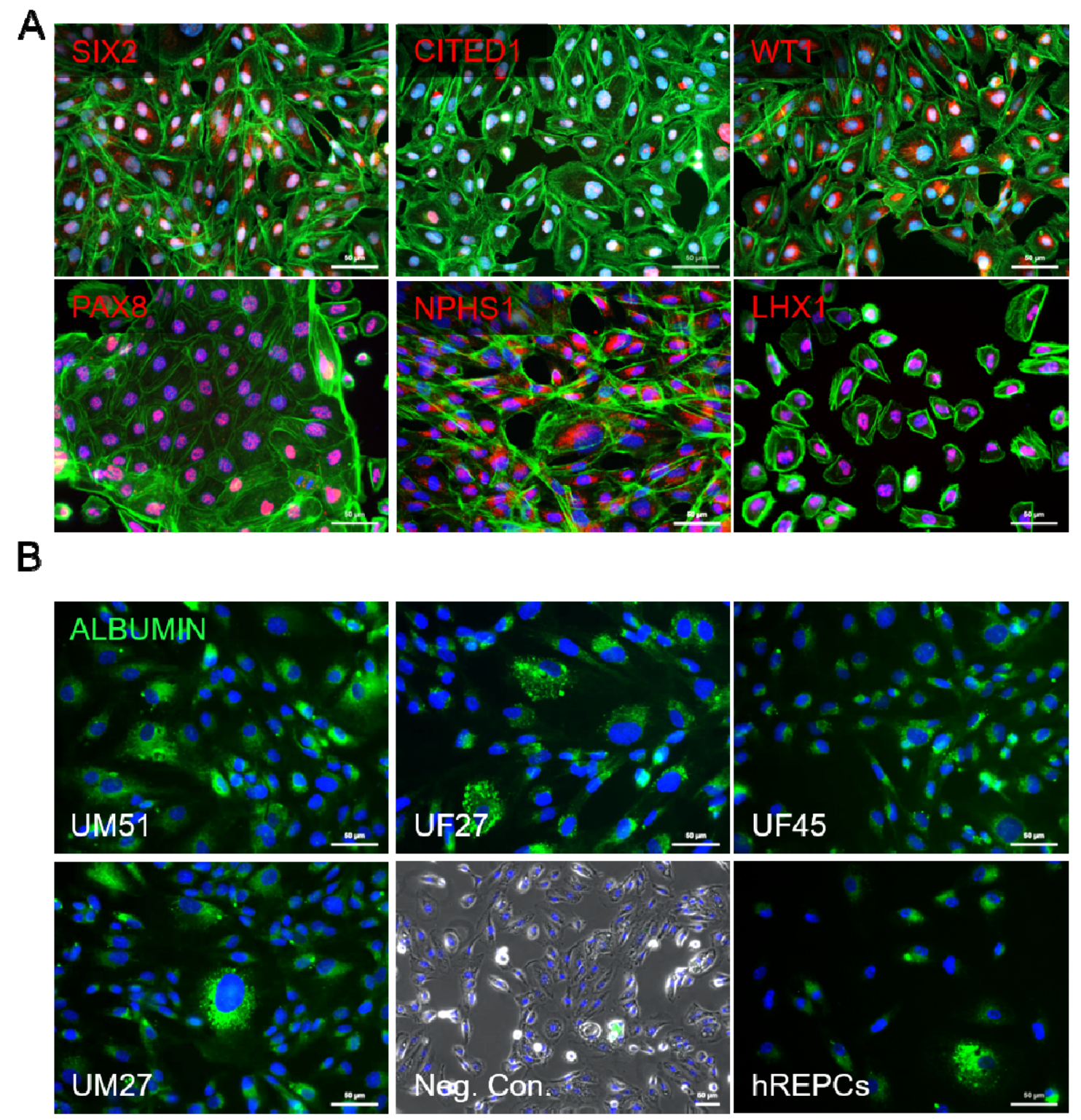
bioRxiv preprint doi: https://doi.org/10.1101/602417; this version posted April 8, 2019. The copyright holder for this preprint (which was not certified by peer review) is the author/funder. All rights reserved. No reuse allowed without permission.

\section{Figure 3}
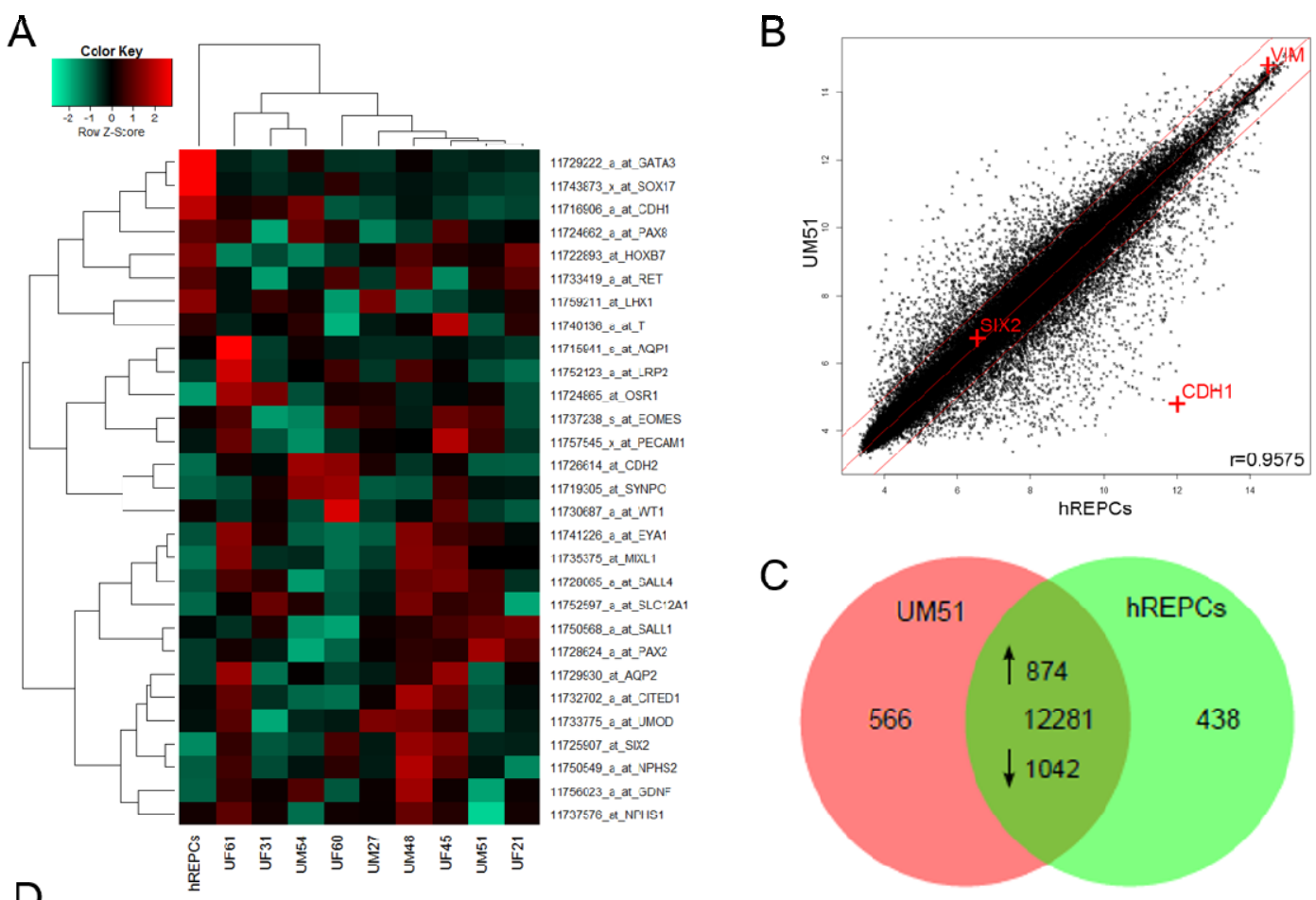

$\begin{array}{ll}\text { Term } & \text { Pvalue } \\ \text { triglyceride homeostasis } & 9,605 \mathrm{E}-06 \\ & \\ \text { kIdney development } & 0,000420 / 8 \\ \text { urogenital system development } & 0,00046036 \\ \text { cullagen fitril uryari<adiur! } & 0,0004605 \\ \text { telencephalon development } & 0,000505 \\ \text { embryonic retina morphogenesis in camera-type eye } & 0,00051672 \\ \text { sonsory organ dovclopmcnt } & 0,00117891 \\ \text { neuronal stem cell population maintenance } & 0,00110151 \\ \text { cell morphogenesis involved in differentiation } & 0,00181875 \\ \text { generation of ovilation cycle rhythm } & 0,00187149\end{array}$

Ierm

Pvalue

prostate epithelial cord arborization involved in

0,00014

prostate glandular acinus morphogenesis

pregulation of branching involvod in prostato gland mo

response to lipopolysaccharide $\quad 0,00012$

inorganic anion transport $\quad 0,00053$

anion transport 0,00056

regulation of icosanoid secretion $\quad 0,00061$

negative regulation of secretion $\quad 0,00072$

prostate glandular acinus development $\quad 0,00102$

cell morphogenesis involved in differentiation _ $\quad 0,00181875$

positive regulation of cytosolic calcium ion concentration $\quad 0,00119$

\begin{tabular}{ll} 
E UM51 up (differentially expressed genes) & \\
& Pvalue \\
\hline $\begin{array}{l}\text { Term } \\
\text { circulatory system development }\end{array}$ & $4,102 \mathrm{E}-12$ \\
positive regulation of RNA biosynthetic process & $4,4896 \mathrm{E}-09$ \\
urogenital system development & $2,3935 \mathrm{E}-08$ \\
anterior/posterior pattern specification & $2,6834 \mathrm{E}-08$ \\
positive regulation of nucleobase-containing & $4,7051 \mathrm{E}-08$ \\
compound metabolic process & $2,6254 \mathrm{E}-07$ \\
positive regulation of biosynthetic process & $9,4143 \mathrm{E}-07$ \\
muscle tissue development & $1,0127 \mathrm{E}-06$ \\
renal tubule development & $1,5071 \mathrm{E}-06$ \\
positive regulation of macromoləcule metabolic process & $2,9227 \mathrm{E}-06$
\end{tabular}

\begin{tabular}{ll}
\multicolumn{2}{c}{ UM51 down (differentially expressed genes) } \\
Term & Pvalue \\
localization of cell & $5,3154 \mathrm{E}-15$ \\
organelle fission & $8,1634 \mathrm{E}-14$ \\
cholesterol biosynthetic process & $7,2679 \mathrm{E}-13$ \\
small molecule biosynthetic process & $8,9168 \mathrm{E}-12$ \\
& \\
cell division & $1,2264 \mathrm{E}-11$ \\
Iegulation or ph Iusphior ylation & $5,8579 \mathrm{E}-11$ \\
regulation of phosphorus metabolic process & $8,1264 \mathrm{E}-11$ \\
organic hydroxy compound biosynthetic process & $8,8558 \mathrm{E}-10$ \\
ncgativo rcgulation of molccular function & $1,045 \mathrm{E} 09$ \\
secondary alcohol metabolic process & $1,4932 \mathrm{E}-09$
\end{tabular}




\section{Figure 4}

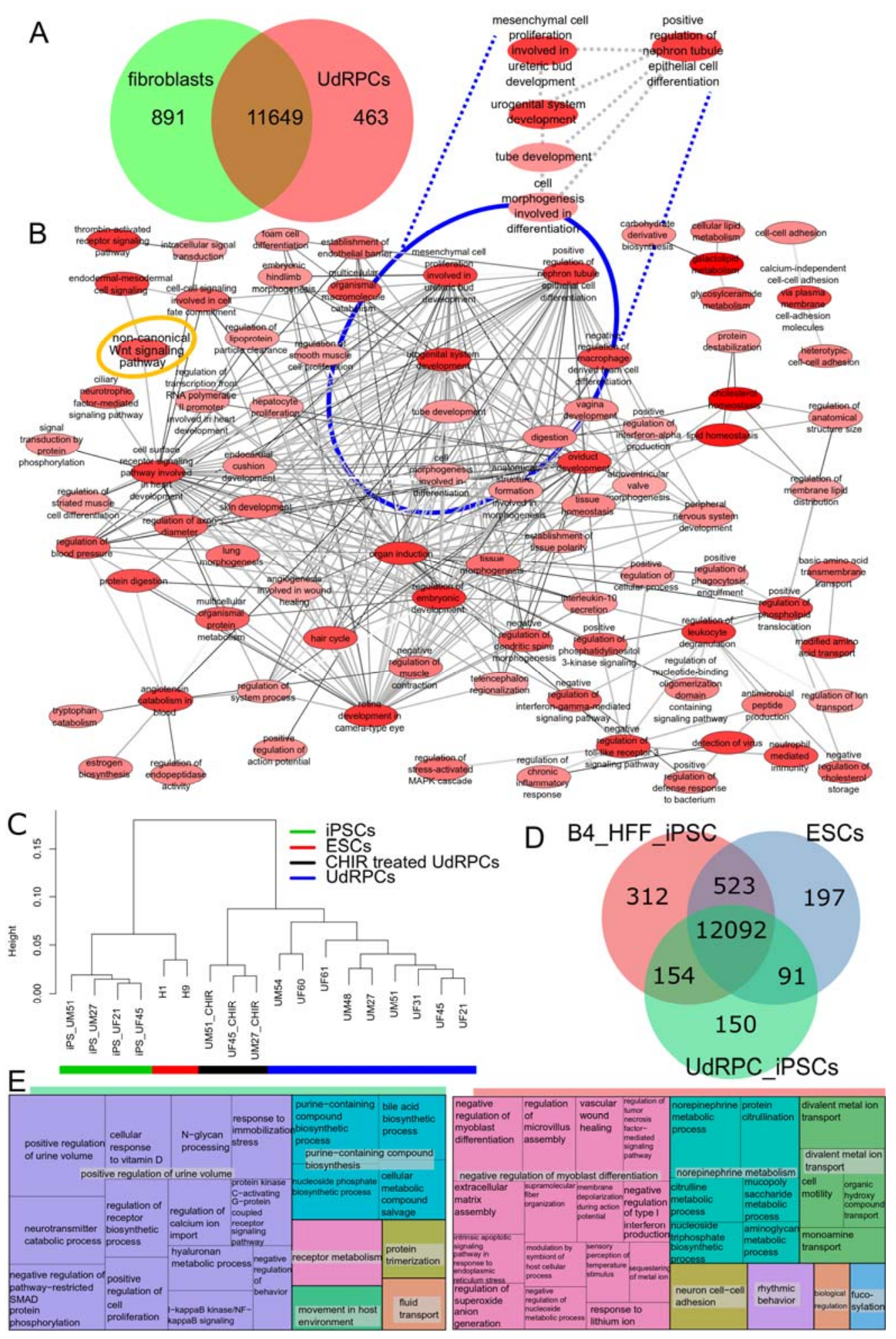




\section{Figure 5}

A

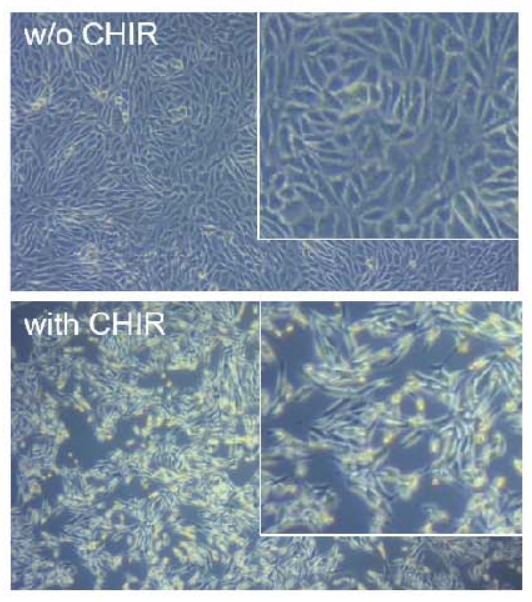

B
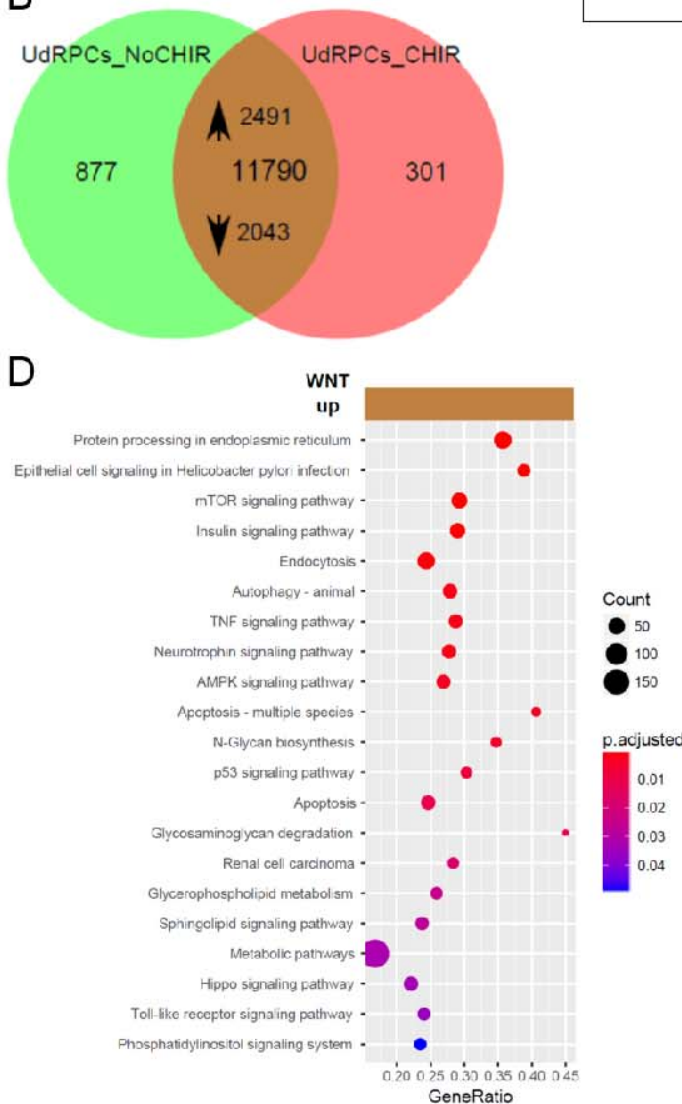

C
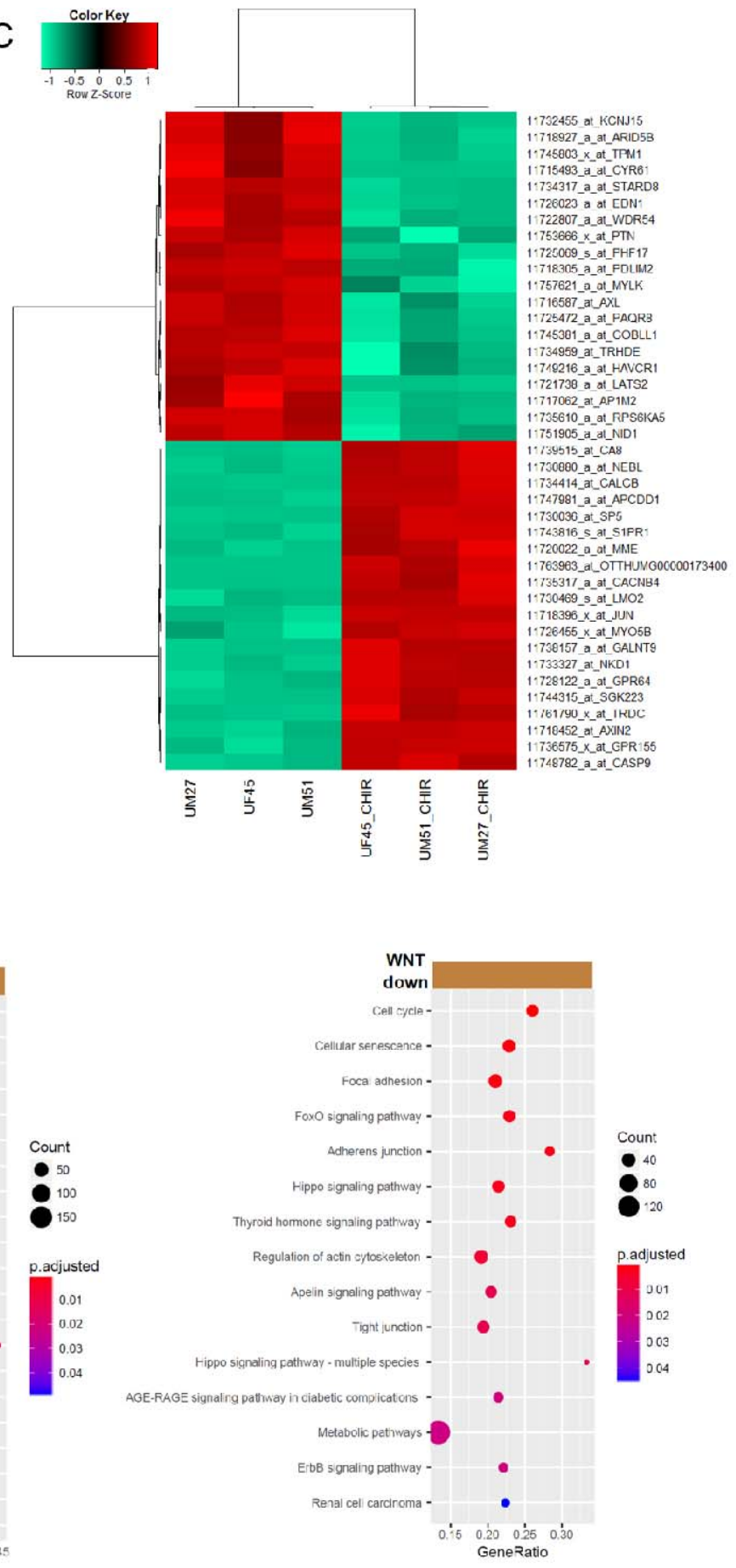


\section{Figure 6}

A

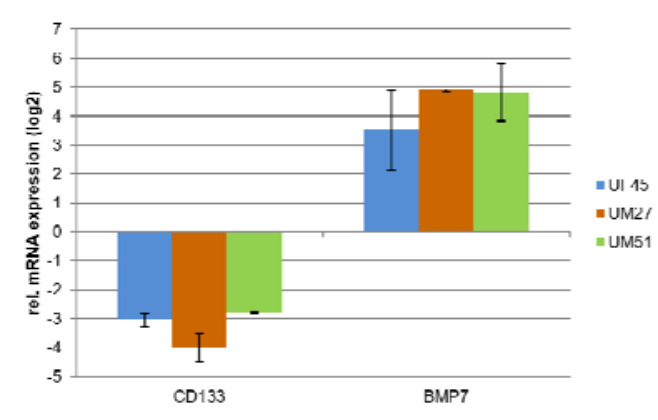

C

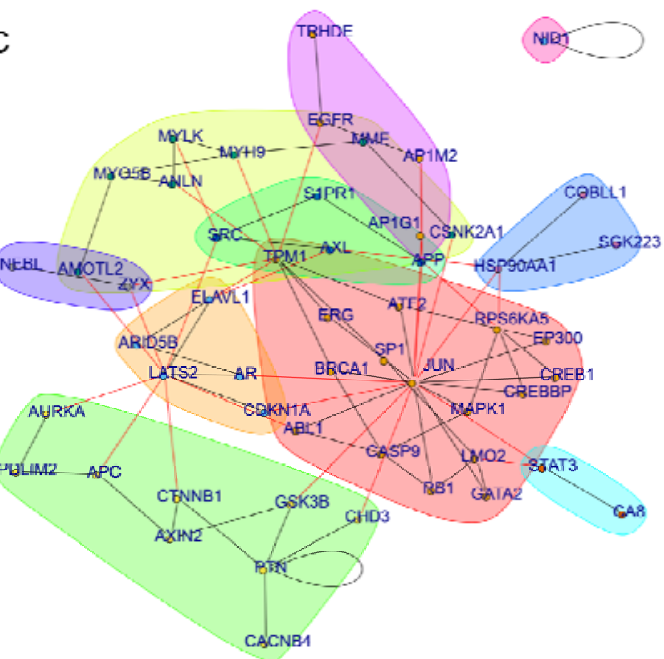

B

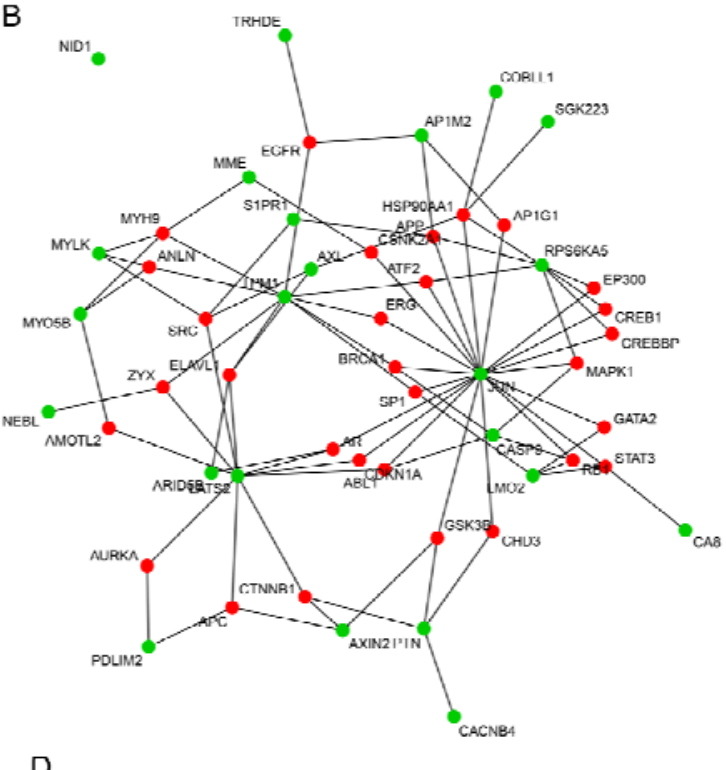

D

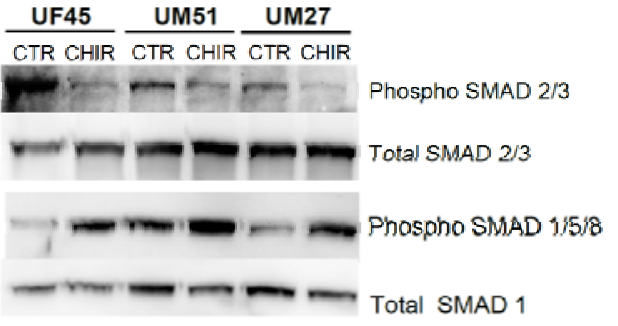




\section{Figure 7}

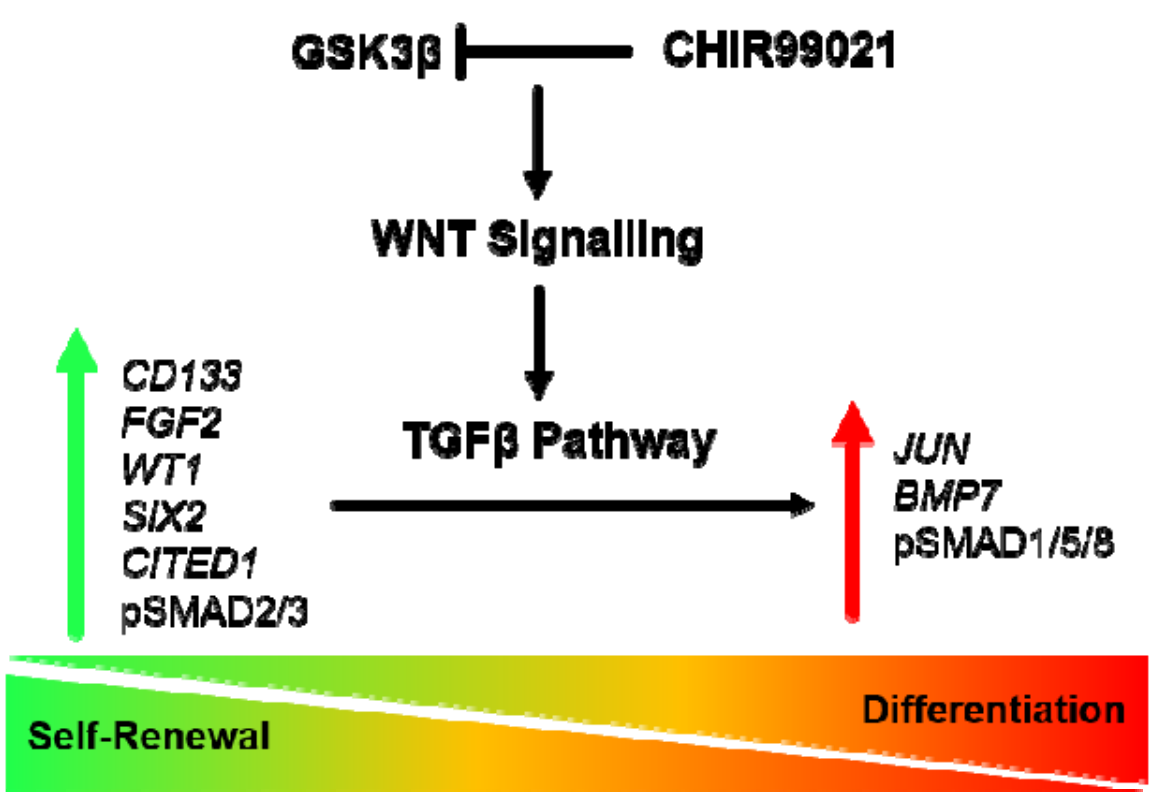




\section{Figure legends}

Figure 1. Propagation and characterisation of UdRPCs. (A) Representative pictures of the "rice grain"-like appearance of the cells from the initial attachment to an elongated MSClike morphology. (B) Growth curve analysis of selected UdRPCs carried out using the Resazurin metabolic assay. Data are presented as means \pm SEMs. (C) Immune-phenotyping and (D) immunofluorescence-based detection of the expression of pluripotency-associated stem cell- proteins (SSEA4 (red), TRA-1-60 (red), TRA-1-81 (red), C-KIT (green), CD133 (green) and the mesenchymal-associated protein Vimentin (green); cell nuclei were stained using Hoechst/DAPI (scale bars: 100 $\mu \mathrm{m}$ ). (E) In vitro Osteoblast, Chondrocyte and Adipocyte differentiation potential of UdRPCs. (F) Cytokines secreted by UdRPCs in culture media. Lists of significant GO's and KEGG pathways associated with the genes encoding the secreted cytokines, are shown in Supplemental Figure S1.

Figure 2. Expression of kidney-associated proteins in UdRPCs and Albumin transport. (A) UdRPCs express the renal markers- SIX2, CITED1, WT1, PAX8, Nephrin (NPHS1) and LHX1. Renal markers (red), phalloidin (green), cell nuclei were stained using DAPI/Hoechst (blue). (B) UdRPCs $(n=4)$ like the human kidney biopsy-derived hREPCs also transport Albumin. Albumin was coupled to Alexa Fluor 488 (green) and cell nuclei stained with DAPI (blue). Scale bars indicate $50 \mu \mathrm{m}$.

Figure 3. Transcriptome analysis of UdRPCs in comparison to kidney biopsy-derived renal epithelial proximal cells- hREPCs. (A) The heatmap of kidney-specific markers expressed in UdRPCs and hREPCs. (B) Comparison of gene expression values of UdRPCs (UM51) with hREPCs in a scatter plot confirms the mesenchymal phenotype of UdRPCs, i.e. expression of Vimentin (VIM) and expression of E-cadherin (CDH1) in hREPCs (C) Expressed genes (det- $p<0.05$ ) in UdRPCs (sample UM51) and hREPCs are compared in the venn diagram. (D) The 10 most over-represented GO BP-terms in 566 UM51 genes include triglyceride homeostasis and kidney development and in $438 \mathrm{hREPCs}$ genes include chloride transmembrane transport. (E) The 10 most over-represented GO BP-terms in the up- and down-regulated genes in UM51 in comparison to hREPCs are shown. The complete dataset is presented in Supplemental Table S3.

Figure 4. In-depth bioinformatic analysis of UdRPCs and UdRPC-iPSCs. (A) Expressed genes (det-p < 0.05) in UdRPCs and fibroblasts are compared in a venn diagram. Most genes are expressed in common (11649), 463 genes are expressed exclusively in UdRPCs and 891 in fibroblasts. The subsets and UdRPCs GOs are presented in supplemental_table_S4. (B) The gene ontology network was generated with the tools 
REVIGO and Cytoscape and summarizes the GO terms of category Biological Process (BP) over-represented in the 463 genes expressed exclusively in UdRPCs. Several general developmental terms emerged, e.g. "organ induction". Specific renal-related terms including "urogenital system development" are marked with a blue ellipse. GOs are represented by network nodes with the intensity of red indicating the significance of over-representation of a GO term. The edges refer to similarities between the GO terms. (C) The dendrogram shows a clear separation of UdRPCs, differentiated UdRPCs (black bar), ESCs ( $\mathrm{H} 1$ and H9, red bar) and UdRPCs-iPSCs (green bar). (D) Venn diagram of HFF-iPSCs, UdRPCs-iPSCs and ESCs. (E) GO terms of 150 genes expressed exclusively in UdRPC-iPSCs indicate that UdRPC-iPSCs retain the memory of renal origin. In the treemap for the HFF-iPSCs the GO$\mathrm{BP}$ terms of the 312 over-represented genes of the exclusive gene set are summarized. The most significant group is associated with negative regulation of myoblast differentiation including genes DDIT3, MBNL3, TGFB1, ZFHX3 pointing at the fibroblast origin of these iPSCs. The entire dataset is presented in Supplemental Table S5.

Figure 5. Supplementation of UdRPCs with the GSK-3 $\beta$ inhibitor. (A) Activation of WNT signalling by supplementation with GSK-3 $\beta$-inhibitor CHIR99021 led to differentiation into renal epithelial proximal tubular cells. (B) Heatmap of 3 independent UdRPC preparations with and without CHIR treatment. (C) In the venn diagram, expressed genes (det- $p<0.05$ ) in untreated UdRPCs are compared to UdRPCs treated with the GSK-3ß-inhibitor CHIR99021. Among the 11790 genes expressed in both conditions, 2491 are up-regulated in the CHIR99021 treatment $(p<0.05$, ratio $>1.33$ ) and 2043 down-regulated $(p<0.05$, ratio < 0.75). (D) Over-representation analysis of the up-regulated genes and associated KEGG pathways revealed protein processing in endoplasmic reticulum as highly significant and several signalling and metabolic pathways including mTOR, Insulin, p53 and TNF. Overrepresentation analysis of the down-regulated genes in KEGG pathways identified cell cycle, cellular senescence, focal adhesion, FoxO and adherens junction as most significant. Supplemental Table S6 provides the full list of regulated genes and associated pathways.

Figure 6. Regulation of self-renewal and differentiation in UdRPCs. (A) Real-time PCRbased confirmation of down-regulation of $C D 133$ and activated expression of BMP7 after CHIR stimulation. (B) JUN is a major hub of protein interaction networks of UdRPCs treated with CHIR. Based on the Biogrid database protein interaction networks were constructed from the set of the most highly regulated 40 genes either up- or down in the UdRPCs treated with CHIR. The selected genes used to connect to the network with interactions from the Biogrid database are marked in green, genes added as Biogrid interactions are marked in red. Induction of WNT leading to GSK3B inhibition is reflected by the connection of GSK3B 
to JUN and to AXIN2 which is connected to CTNNB1 ( $\beta$-catenin) - these all downstream targets of GSK3B in the WNT-signaling pathway. (C) Community clustering of the network identified several communities: JUN (red), GSK3B/AXIN2/CTNNB1 (green), LATS2 (yellow), EGFR (pink). Black lines refer to edges within a community, red lines to edges between different communities. (D) Western blot analysis of the phosphorylated levels of SMAD 2/3 and SMAD 1/5/8 in undifferentiated and differentiated UF45, UM51 and UM27.

Figure 7. WNT $\beta$ catenin and TGF $\beta$ pathway-mediated cell fate decisions in UdRPCs. Self-renewal (inactive WNT/ $\beta$ catenin signalling and active TGF $\beta$-SMAD2/3 signalling) is maintained by elevated expression of the renal progenitor markers SIX2, WT1, CITED1, CD133, in addition to phospho-SMAD2/3 and FGF2 resulting in and down regulated expression of BMP7. In contrast, activation of WNT/ $\beta$-catenin signalling induces upregulated expression of JUN and BMP7 leading to activation of phospho-SMAD1/5/8, downregulated expression of WT1, SIX2, CITED1, FGF2, CD133 and ultimately exit of self-renewal. 


\section{Supplemental Material Table of Contents}

\begin{tabular}{|c|c|}
\hline $\begin{array}{l}\text { Supplemental } \\
\text { Number }\end{array}$ & Legends \\
\hline $\begin{array}{l}\text { Supplemental } \\
\text { Figure S1 }\end{array}$ & $\begin{array}{l}\text { Detailed analysis by bisulfite sequencing of CpG island methylation patterns within } \\
\text { the } 5^{\prime} \text { - regulatory region of the OCT4 gene in UM51 (control) and its iPSC derivative. } \\
\text { Detailed CpG methylation profiles of the OCT4 } 5^{\prime} \text {-regulatory region are documented } \\
\text { as revealed by bisulfite sequencing. Filled circles (black) denote methylated CpG } \\
\text { dinucleotides, white denote unmethylated CpGs and gray CpG dinucleotides of } \\
\text { unknown methylation status. Arrows indicate the transcription start site. }\end{array}$ \\
\hline $\begin{array}{l}\text { Supplemental } \\
\text { Figure S2 }\end{array}$ & $\begin{array}{l}\text { (A) Immuno-phenotyping for MSC markers. (B) Secretome profile membrane. (C) } \\
\text { Secretome genes related GOs and KEGG Pathways. (D) PODXL and CK19 staining. }\end{array}$ \\
\hline $\begin{array}{l}\text { Supplemental } \\
\text { Figure S3 }\end{array}$ & Generation and characterization of iPSCs from UdRPCs. \\
\hline $\begin{array}{l}\text { Supplemental } \\
\text { Figure S3_A }\end{array}$ & $\begin{array}{l}\text { (A) The reprogrammed vector-free UdRPCs-iPSCs stained positive for the } \\
\text { transcription factors Oct4, Sox } 2 \text { and Nanog and for the surface markers TRA-1-60, } \\
\text { TRA-1-81 and SSEA-4 confirmed by immunofluorescence. }\end{array}$ \\
\hline $\begin{array}{l}\text { Supplemental } \\
\text { Figure S3_B }\end{array}$ & $\begin{array}{l}\text { (B) The immunofluorescence-based study shows a successful undirected } \\
\text { differentiation into the mesoderm lineage detected with the mesoderm marker a-SMA } \\
\text { and a successful specification along the endoderm layer confirmed with AFP, as well } \\
\text { as the ectoderm layer proved with Nestin. }\end{array}$ \\
\hline $\begin{array}{l}\text { Supplemental } \\
\text { Figure S3_C }\end{array}$ & $\begin{array}{l}\text { (C) Dendrogram resulting from hierarchical clustering of global gene expression } \\
\text { profiles of UdRPCs-iPSCs, UdRPCs, and established ESCs (H1, H9). } \\
\text { Transcriptomes of UdRPCs-iPSCs cluster with H1, H9 while those of the UdRPCs } \\
\text { cluster separately. Pearson correlation analysis of transcriptome data revealed a } \\
\text { high correlation (green) of UdRPCs-iPSCs with ESCs but low correlation with } \\
\text { UdRPCs. Pearson's correlation coefficient was calculated in which each replicate } \\
\text { was pairwise compared with each other replicate. A value of } 1 \text { indicates perfect linear } \\
\text { correlation while a value of } 0 \text { implies no correlation. }\end{array}$ \\
\hline $\begin{array}{l}\text { Supplemental } \\
\text { Figure S3_D }\end{array}$ & $\begin{array}{l}\text { (D) The origin of the formed iPSCs was assigned to its donor UdRPC line by } \\
\text { determining the individual DNA signature. For this purpose, a PCR-based DNA } \\
\text { fingerprinting using specific primer sets, which amplify different VNTRs (variable } \\
\text { number of tandem repeats) was employed. Ultimately, the genotyping provide } \\
\text { evidence, that reprogrammed iPSC clones originate from their parental UdRPC line } \\
\text { and hence exclude the possibility of cross-contamination. Collecting all data, the } \\
\text { excellent quality and integrity of the reprogrammed urinary progenitor cells was } \\
\text { proven by a normal } 46, X Y \text { karyotype. }\end{array}$ \\
\hline $\begin{array}{l}\text { Supplemental } \\
\text { Figure S4 }\end{array}$ & $\begin{array}{l}\text { ESC-exclusively GOs when compared to HFF-iPSCs and UdPC-iPSCs. Treemap } \\
\text { summarizing the GO-BP terms overrepresented in the } 197 \text { genes expressed } \\
\text { exclusively in ESCs. The largest most significant group is associated with "negative } \\
\text { regulation of astrocyte differentiation", second comes "anion transmembrane } \\
\text { transport". }\end{array}$ \\
\hline $\begin{array}{l}\text { Supplemental } \\
\text { Figure S5 }\end{array}$ & genes up and down regulated upon CHIR treatment \\
\hline
\end{tabular}




\section{Supplemental Material Table of Contents}

\begin{tabular}{|c|c|}
\hline $\begin{array}{l}\text { Supplemental } \\
\text { Number }\end{array}$ & Legends \\
\hline $\begin{array}{c}\text { Supplemental } \\
\text { Table S1 }\end{array}$ & List of Antibodies used for immunocytochemistry/flow-cytometry. \\
\hline $\begin{array}{c}\text { Supplemental } \\
\text { Table S2 }\end{array}$ & List of primers \\
\hline $\begin{array}{l}\text { Supplemental } \\
\text { Table S3 } \\
\text { (Excel file) }\end{array}$ & $\begin{array}{l}\text { Sheet 1: Subsets of venn diagram comparison of UdRPCs of sample UM51 vs. } \\
\text { hREPCs. } \\
\text { Sheet 2: Overrepresented GOs in the exclusive UM51 subset with } 566 \text { genes from } \\
\text { the venn diagram comparison of UdRPCs of sample UM51 vs. hREPCs. } \\
\text { Sheet 3: Overrepresented GOs in the exclusive hREPCs subset with } 438 \text { genes from } \\
\text { the venn diagram comparison of UdRPCs of sample UM51 vs. hREPCs. } \\
\text { Sheet 4: Overrepresented GOs in the up-regulated genes (limma-p-value }<0.05 \text {, } \\
\text { ratio > 2) from the overlap subset of the venn diagram comparison of UdRPCs of } \\
\text { sample UM51 vs. hREPCs. } \\
\text { Sheet 5: Overrepresented GOs in the down-regulated genes (limma-p-value }<0.05 \text {, } \\
\text { ratio < } 0.5 \text { ) from the overlap subset of the venn diagram comparison of UdRPCs of } \\
\text { sample UM51 vs. hREPCs }\end{array}$ \\
\hline $\begin{array}{l}\text { Supplemental } \\
\text { Table S4 } \\
\text { (Excel file) }\end{array}$ & $\begin{array}{l}\text { Sheet 1: Subsets of venn diagram comparison of UdRPCs vs. fibroblasts. } \\
\text { Sheet 2: Overrepresented GOs in the exclusive UdRPC subset with } 463 \text { genes from } \\
\text { the venn diagram comparison of UdRPCs vs. fibroblasts }\end{array}$ \\
\hline $\begin{array}{l}\text { Supplemental } \\
\text { Table S5 } \\
\text { (Excel file) }\end{array}$ & $\begin{array}{l}\text { Sheet 1: Subsets of venn diagram comparison of iPSCs derived from UdRPCs } \\
\text { (UdRPC_iPSCs), iPSCs derived from human foreskin fibroblasts (B4_HFF_iPSCs) } \\
\text { and human embryonic stem cells (ESCs). } \\
\text { Sheet 2: Overrepresented GOs in the exclusive UdRPC_iPSCs subset with } 150 \\
\text { genes from the venn diagram comparison of UdRPC_iPSCs, B4_HFF_iPSCs and } \\
\text { ESCs. } \\
\text { Sheet 3: Overrepresented GOs in the exclusive B4_HFF_iPSCs subset with } 312 \\
\text { genes from the venn diagram comparison of UdRPC_iPSCs, B4_HFF_iPSCs and } \\
\text { ESCs. } \\
\text { Sheet 4: Overrepresented GOs in the exclusive ESCs subset with } 197 \text { genes from } \\
\text { the venn diagram comparison of UdRPC_iPSCs, B4_HFF_iPSCs and ESCs. }\end{array}$ \\
\hline $\begin{array}{l}\text { Supplemental } \\
\text { Table S6 } \\
\text { (Excel file) }\end{array}$ & $\begin{array}{l}\text { Sheet 1: Subsets of venn diagram comparison of UdRPCs treated with CHIR99021 } \\
\text { vs. untreated UdRPCs. } \\
\text { Sheet 2: The set of } 2491 \text { up-regulated genes ( } p<0.05 \text {, ratio }>1.33 \text { ) from the venn } \\
\text { diagram intersection of UdRPCs treated with CHIR99021 vs. untreated UdRPCs. } \\
\text { Sheet 3: The set of } 2043 \text { down-regulated genes ( } p<0.05 \text {, ratio<0.75) from the venn } \\
\text { diagram intersection of UdRPCs treated with CHIR99021 vs. untreated UdRPCs. } \\
\text { Sheet 4: The set of } 7255 \text { not regulated genes ( } p>0.05,0.75<\text { ratio }<1.33 \text { ) from the } \\
\text { venn diagram intersection of UdRPCs treated with CHIR99021 vs. untreated } \\
\text { UdRPCs. } \\
\text { Sheet 5: Overrepresented KEGG pathways in the set of } 2491 \text { up-regulated genes } \\
\text { from the venn diagram intersection of UdRPCs treated with CHIR99021 vs. untreated } \\
\text { UdRPCs. } \\
\text { Sheet 6: Overrepresented KEGG pathways in the set of } 2043 \text { down-regulated genes } \\
\text { from the venn diagram intersection of UdRPCs treated with CHIR99021 vs. untreated } \\
\text { UdRPCs. } \\
\text { Sheet 7: Novel genes beginning with LOC (without published symbol) in the set of } \\
2491 \text { up-regulated genes ( } p<0.05 \text {, ratio }>1.33 \text { ) from the venn diagram intersection of } \\
\text { UdRPCs treated with CHIR99021 vs. untreated UdRPCs. } \\
\text { Sheet } 8 \text { : Novel genes beginning with LOC (without published symbol) in the set of } \\
2043 \text { down-regulated genes ( } p<0.05 \text {, ratio }<0.75) \text { from the venn diagram intersection } \\
\text { of UdRPCs treated with CHIR99021 vs. untreated UdRPCs. } \\
\text { Sheet } 9 \text { : Novel genes beginning with LOC (without published symbol) in the set of } \\
7255 \text { down-regulated genes ( }>0.05,0.75<\text { ratio }<1.33 \text { ) from the venn diagram } \\
\text { intersection of UdRPCs treated with CHIR99021 vs. untreated UdRPCs. }\end{array}$ \\
\hline
\end{tabular}




\section{Supplemental Material and Methods}

\section{UdRPCs differentiation}

For differentiation of the UdRPCs $10 \mu \mathrm{M}$ CHIR99021 was added to the cell culture medium for 2 days. Adult kidney biopsy derived primary human renal epithelial cells (hREPCs) (C12665, Promo Cell, Heidelberg, Germany) were used as control.

\section{Immunophenotyping by flow cytometry}

The analysis of MSC-associated cell surface marker expression of UdRPCs was performed using MSC Phenotyping Kit (Miltenyi) according to the manufacturer's instructions. In case of pluripotency-associated markers, TRA-1-60, TRA-1-81, and SSEA4 dye-coupled antibodies were used (anti-TRA-1-60-PE, human (clone: REA157), number 130-100-347; anti-TRA-181-PE, human (clone: REA246), number 130-101-410, and anti-SSEA-4-PE, human (clone: REA101), number 130-098-369; Miltenyi Biotec GmbH). Flow cytometric analysis of the stained cells was performed via BD FACSCanto (BD Biosciences, Heidelberg, Germany) and CyAn ADP (Beckman Coulter, CA, USA). Histograms were generated using the Summit 4.3.02 software.

\section{RNA isolation and cDNA synthesis}

RNA was isolated using the Direct-zol RNA MiniPrep Kit (Zymo Research, CA, USA) according to provider guidelines. After checking the quality of mRNA, 500 ng of RNA were used for complementary DNA synthesized with the TaqMan Reverse Transcription Kit (Applied Biosystems).

\section{Culture supernatant analysis}

For the detection of cytokines secreted by the UdRPCs, we employed the Proteome Profiler Human Cytokine Array Panel A (R\&D Systems, MA, USA) following the manufacturer's instructions. $1.5 \square \mathrm{ml}$ of conditioned medium from cultured UdRPCs at a density of $95 \%$ was 
used. The array was evaluated by detection of the emitted chemiluminescence. The pixel density of each spotted cytokine was analysed using the software ImageJ. All spots on the membrane including reference and negative control spots were measured separately. Correlation variations and $p$ values were calculated based on the pixel density.

\section{Differentiation into adipocytes, chondrocytes and osteoblasts}

Differentiation of UdRPCs into adipocytes, chondrocytes and osteoblasts were tested using the StemPro Adipogenesis, Chondrogenesis, and Osteogenesis differentiation Kits (Gibco, Life Technologies, CA, USA). After the differentiation periods, cells were fixed using 4\% PFA for $20 \mathrm{~min}$ at RT and stained with Oil Red-O for detecting adipocytes, Alcian Blue for chondrocytes, and Alizarin Red S for osteoblasts as described previously. A light microscope was used for imaging.

\section{Generation of iPSC from UdRPCs}

UdRPCs were reprogrammed into iPSCs using an integration-free episomal based transfection system without pathway inhibition. Briefly, UdRPCs were nucleofected with two plasmids pEP4 E02S ET2K (Addgene plasmid \#20927) and pEP4 E02S CK2M EN2L (Addgene plasmid \#20924) expressing a combination of pluripotency factors including OCT4, SOX2, LIN28, c-MYC, KLF4, and NANOG using the Amaxa 4D-Nucleofector Kit according to the manufacturer's guidelines and as described previously. The nucleofected cells were cultured on Matrigel coated 6-well plate containing StemMACs or mTeSR media under hypoxic conditions. Emerging colonies were picked and transferred to a new plate and cultured under normoxic conditions. After few passaging, vector-dilution PCR and genomic DNA fingerprinting were performed. Karyotyping was performed at the Institute of Human Genetics and Anthropology, Heinrich Heine University, Düsseldorf. Finally, embryoid body (EB) formation and analysis were carried out. 


\section{Immunofluorescence-based detection of protein expression}

To analyse expression of specific markers, cells were fixed with 4\% PFA (Polysciences Inc., PA, USA) for $15 \mathrm{~min}$ at room temperature (RT) and washed three times in PBS and permeability was increased using $1 \%$ Triton $\mathrm{X}-100$ for 5 min. Next, for blocking we used: 10\% normal goat serum (NGS; Sigma), 0.5\% Triton X-100, 1\% BSA (Sigma) and 0.05\% Tween 20 (Sigma) in PBS for $2 \mathrm{~h}$. The cells were incubated with primary antibodies (Supplementary Table S1) for $1 \mathrm{~h}$ at RT followed by three washes with PBS. Thereafter the corresponding secondary Cy3-labeled or Alexa Fluor 488-labeled antibodies (Thermo Fisher Scientific) and Hoechst 33,258 dye (Sigma-Aldrich Chemie GmbH, Taufkirchen, Germany) or DAPI (Southern Biotech) were added. A fluorescence microscope (LSM700; Zeiss, Oberkochen, Germany) was used for taking the pictures. All pictures were processed with the ZenBlue 2012 Software Version 1.1.2.0. (Carl Zeiss Microscopy GmbH, Jena, Germany).

\section{Albumin endocytosis assay}

UdRPCs were plated at a density of $40 \%$ without coating. After two days the cells were washed 1X with PBS and incubated in new medium contained $20 \mu \mathrm{g} / \mathrm{ml}$ of bovine serum albumin (BSA)-Alexa Fluor 488 conjugate (catalog no. A13100; Thermo Fischer) for $1 \mathrm{~h}$ at $37^{\circ} \mathrm{C}$. Thereafter, the cells were washed three times with ice-cold PBS and fixed with $4 \%$ PFA for $15 \mathrm{~min}$. Cell-associated fluorescence was analyzed using an excitation wavelength of $488 \mathrm{~nm}$ and an emission wavelength of $540 \mathrm{~nm}$ and imaged using a florescence microscope (LSM700; Zeiss, Oberkochen, Germany).

\section{Western blot analysis}

For protein extraction, cells were harvested and lysed in RIPA buffer (Sigma Aldrich) supplemented with complete protease and phosphatase inhibitors cocktail (Roche). The lysates were separated on a $4-20 \%$ Bis-Tris gel and blotted onto a $0.45 \mu \mathrm{m}$ nitrocellulose membrane (GE Healthcare Life Sciences). The membranes were then blocked with 5\% skimmed milk in Tris-Buffered Saline Tween (TBS-T) and incubated overnight with the 
respective primary antibodies: Total Smad 1 (CST, 1:1000, TBS-T 5\% BSA), phospho Smad 1/5/8 (CST, 1:1000, TBS-T 5\% milk), Total Smad 2/3 (CST, 1:1000, TBS-T 5\% BSA), and phospho Smad 2/3 (CST, 1:1000, TBS-T 5\% milk). After incubation with the appropriate secondary antibodies, signals were acquired with a Fusion-FX7 imaging system.

\section{Analysis of cell proliferation}

Cell proliferation were analysed using resazurin metabolic colorimetric assay. UdRPCs were seeded $\left(1 \times 10^{4}\right.$ cells/well) in a 6 -well plate and incubated at $37^{\circ} \mathrm{C}$ in a humidified atmosphere at $5 \% \mathrm{CO}_{2}$. The medium was substituted with $10 \%$ of a resazurin solution $(0.1 \mathrm{mg} / \mathrm{ml}$ resazurin salt solution (Sigma- Aldrich) in PBS) with an end-volume of $2 \mathrm{ml}$ per well and changed on daily basis. The cultures were incubated for $4 \mathrm{~h}$ at $37^{\circ} \mathrm{C}$ in $5 \% \mathrm{CO}_{2}$. Following this incubation period, the resazurin-containing medium was collected and the rate of resazurin conversion to resofurin by metabolically active cells was evaluated by spectrophotometric analysis at 570 and $600 \mathrm{~nm}$. A final optical density (O.D.f) was determined for each sample, as follows: (O.D. 570/O.D.600)-(O.D.570c/O.D. c 600), where 'OD.c' are the O.D.s of control samples (fresh medium supplemented with resazurin, never in contact with cells). This procedure was carried out for 9 days, at the same hour, in triplicate.

\section{Cell lines used in this study and culture condition}

The fibroblast cell used in this study were obtained from human foreskin fibroblast (HFF1) (ATCC, \#ATCC-SCRC-1041, Manassas, VA, USA, www.atcc.org). Pluripotent stem cells (HFF-iPSCs (human foreskin fibroblast-derived induced pluripotent stem cells (iPSCs)) and ESCs (H1 (\#WA01) and H9 (\#WA09), WiCell Research Institute, Madison, WI, USA, www.wicell.org) were cultured in mTeSR on cell culture dishes coated with Matrigel (BD). Media were replaced change every day. Passaging of pluripotent stem cells was carried out with a splitting ratio of $1: 3$ to $1: 10$. Passaging was conducted manually using a syringe needle and a pipette under a binocular microscope or using a cell scraper and PBS (--). 


\section{$\begin{array}{ll}\text { A } & B\end{array}$}

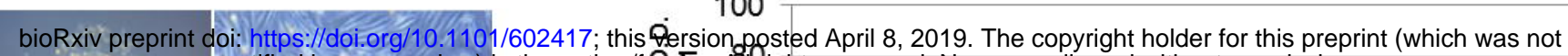
certified by peer review) is the author/flifider. Aql Pights reserved. No reuse allowed without permission.

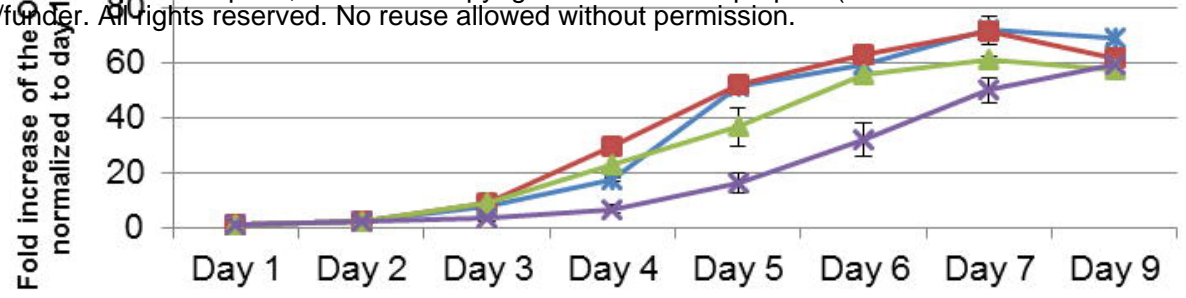

$$
\text { *-UM27 -UM16 -UM51 } \rightarrow \text { UF45 }
$$

C
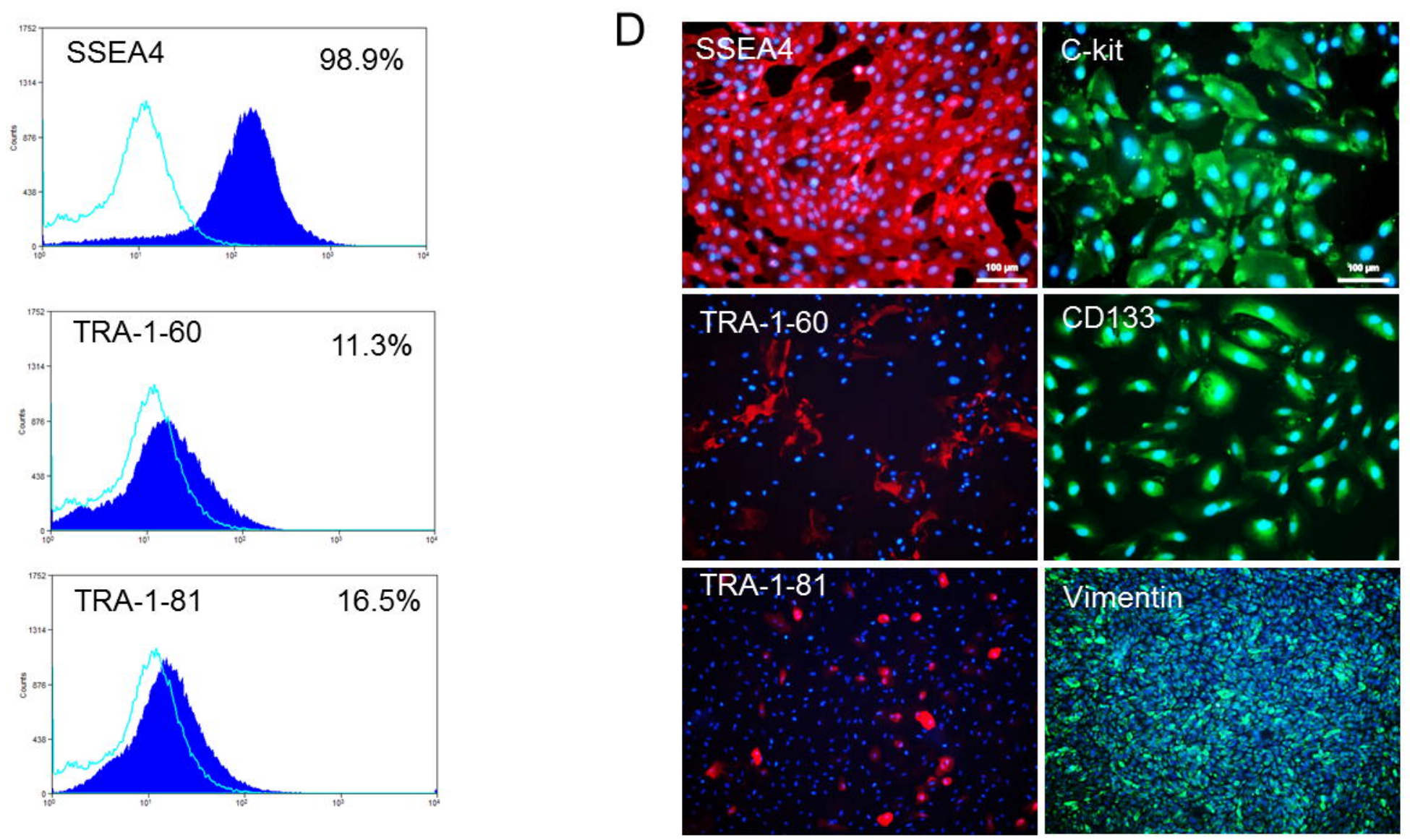

$E$
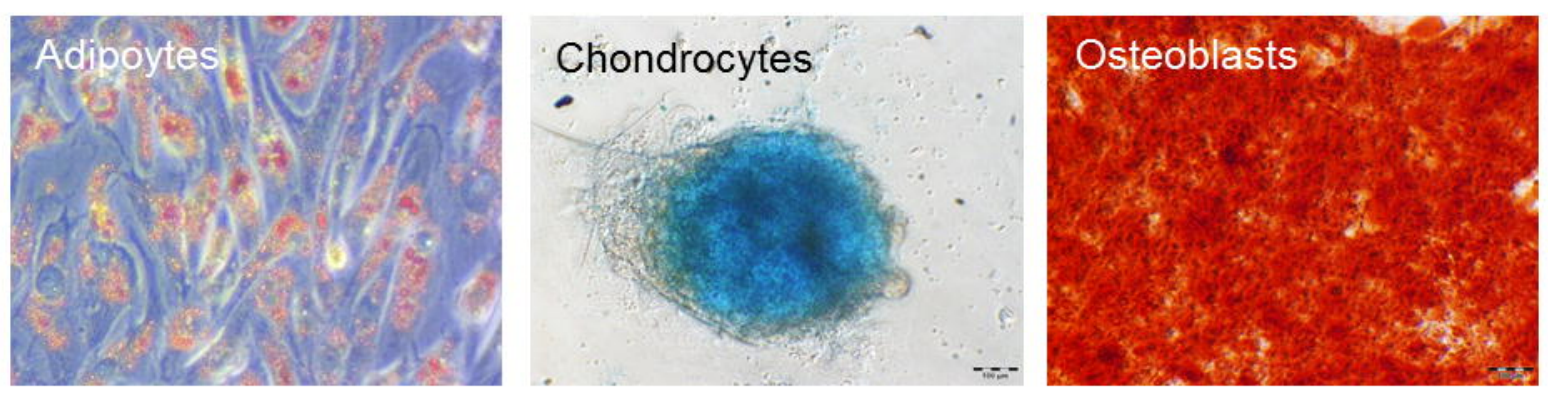

F
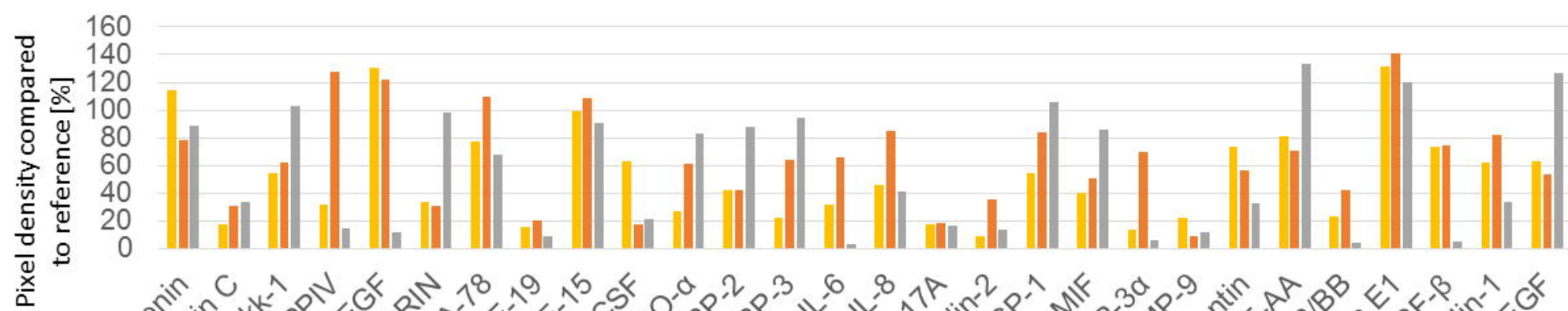

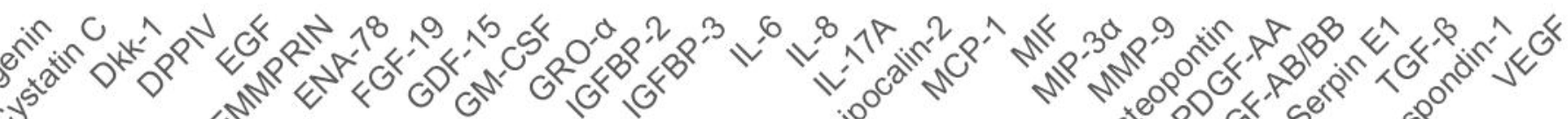




\section{$A$}

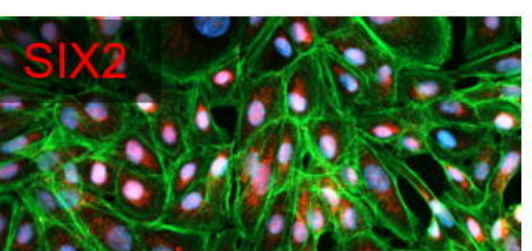

Q9.

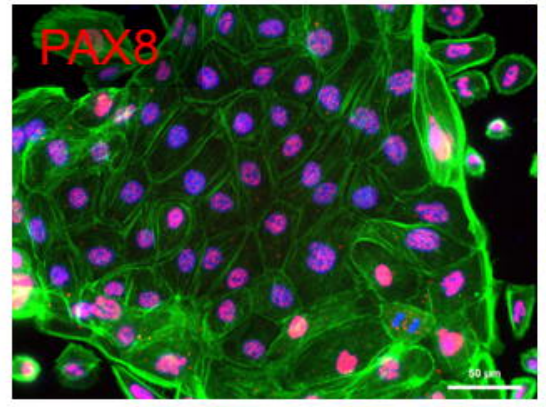

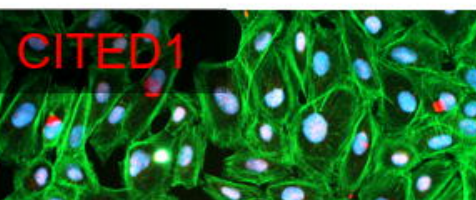

$\because 0.0 \%$

- $20=$ : $: 0 \div$

020.20

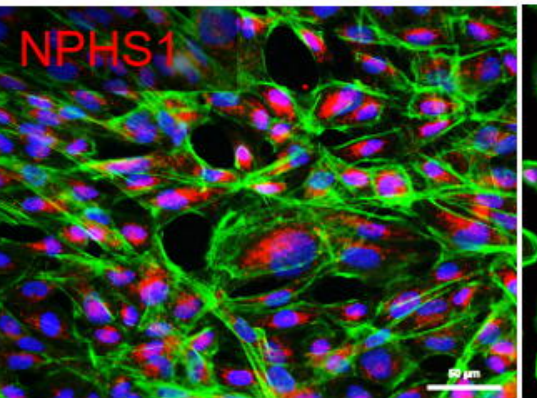

$\mathrm{LHX}$

* a 0

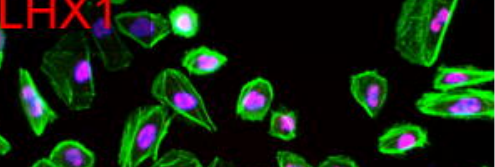

की e)

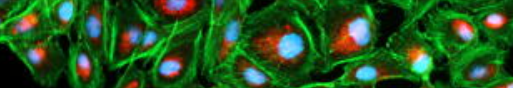

B

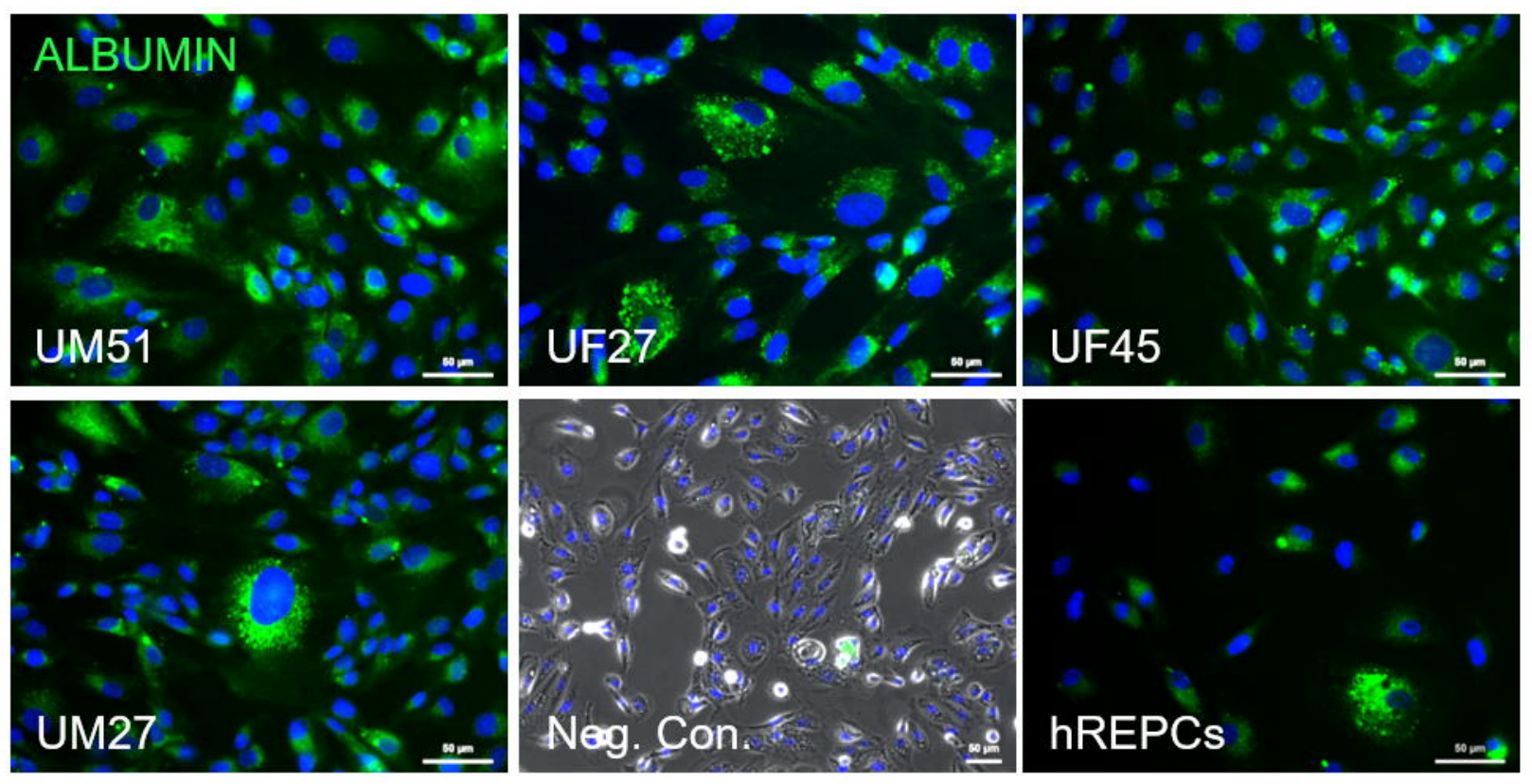


A

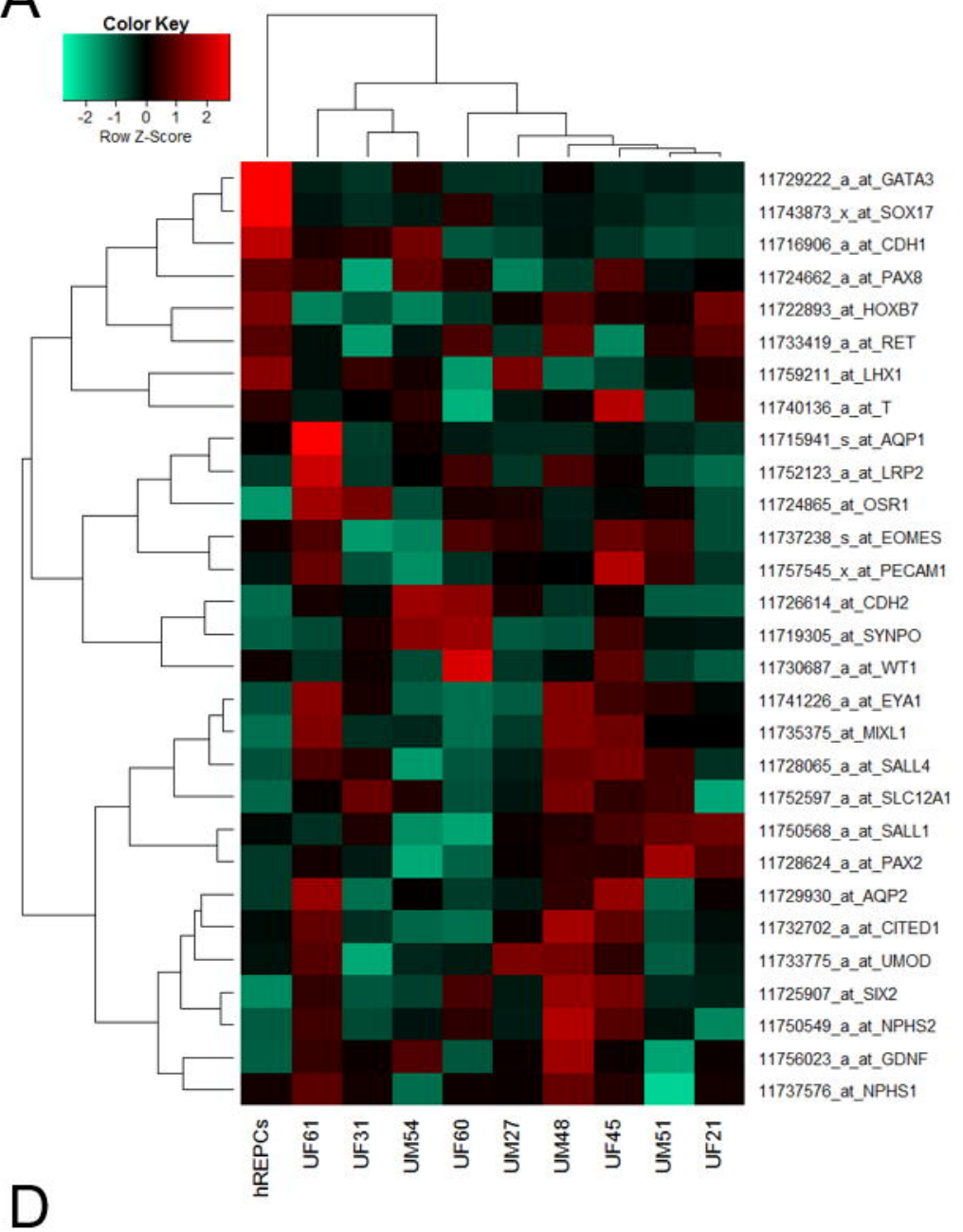

B

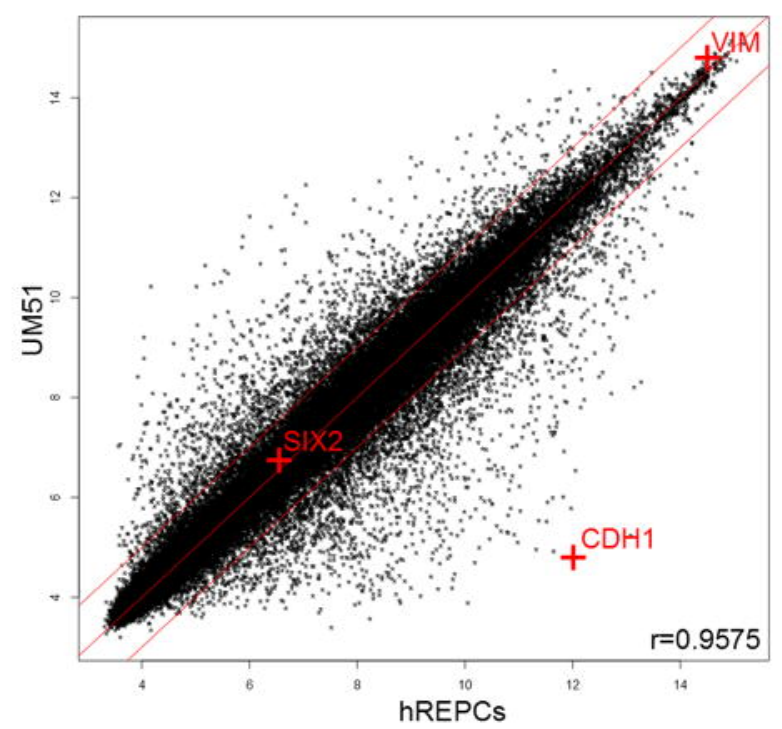

C

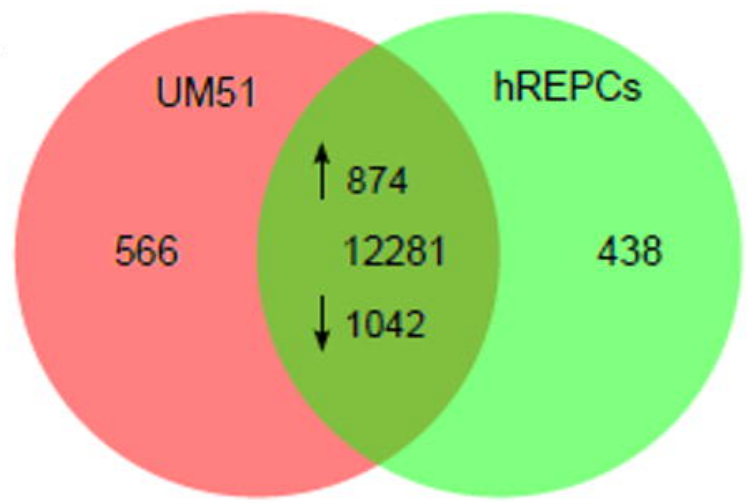

Term

triglyceride homeostasis

kidney development

urogenital system development

collagen fibril organization

telencephalon development

embryonic retina morphogenesis in camera-type eye

sensory organ development

neuronal stem cell population maintenance

cell morphogenesis involved in differentiation

generation of ovulation cycle rhythm
Pvalue

9,605E-06

0,00042078

0,00046036

0,0004605

0,000505

0,00051672

0,00117891

0,00140151

0,00181875

0,00187149

\section{$\mathrm{E}$}

.

\section{p}

\section{UM51 up (differentially expressed genes)}

Term

circulatory system development

positive regulation of RNA biosynthetic process

urogenital system development

anterior/posterior pattern specification

positive regulation of nucleobase-containing

compound metabolic process

positive regulation of biosynthetic process

muscle tissue development

renal tubule development

positive regulation of macromolecule metabolic process

tissue morphogenesis
Pvalue

4,102E-12

4,4896E-09

2,3935E-08

$2,6834 \mathrm{E}-08$

4,7051E-08

2,6254E-07

9,4143E-07

1,0127E-06

1,5071E-06

2,9227E-06

\section{Term}

chloride transmembrane transport

Pvalue

prostate epithelial cord arborization involved in

prostate glandular acinus morphogenesis

0,00014

regulation of branching involved in prostate gland morphogenesis 0,00031

response to lipopolysaccharide

0,00042

0,00053

0,00056

anion transport

regulation of icosanoid secretion

0,00061

0,00072

negative regulation of secretion

0,00102

positive regulation of cytosolic calcium ion concentration

\begin{tabular}{ll}
\multicolumn{2}{c}{ UM51 down (differentially expressed genes) } \\
\hline Term & Pvalue \\
localization of cell & $5,3154 \mathrm{E}-15$ \\
organelle fission & $8,1634 \mathrm{E}-14$ \\
cholesterol biosynthetic process & $7,2679 \mathrm{E}-13$ \\
small molecule biosynthetic process & $8,9168 \mathrm{E}-12$ \\
& \\
cell division & $1,2264 \mathrm{E}-11$ \\
regulation of phosphorylation & $5,8579 \mathrm{E}-11$ \\
regulation of phosphorus metabolic process & $8,1264 \mathrm{E}-11$ \\
organic hydroxy compound biosynthetic process & $8,8558 \mathrm{E}-10$ \\
negative regulation of molecular function & $1,045 \mathrm{E}-09$ \\
secondary alcohol metabolic process & $1,4932 \mathrm{E}-09$
\end{tabular}


A

mesenchymal cell

positive

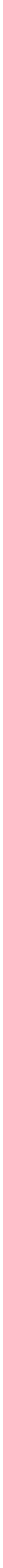

C

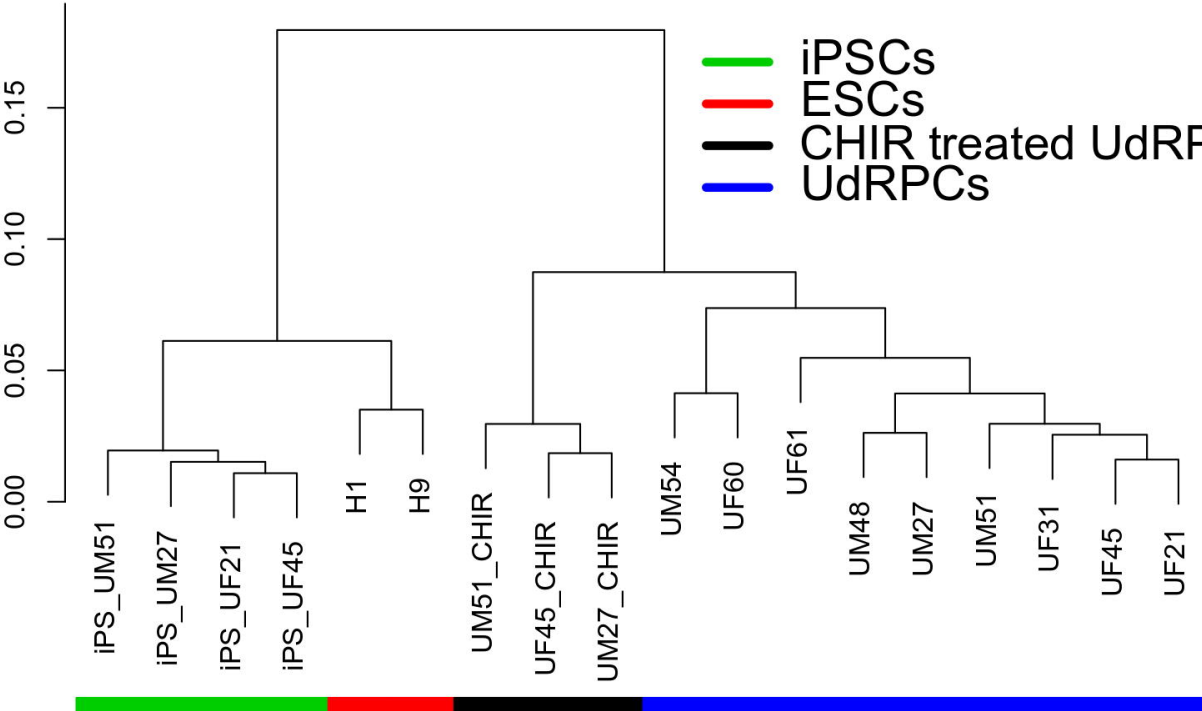

D B4_HFF_iPSC

ESCs
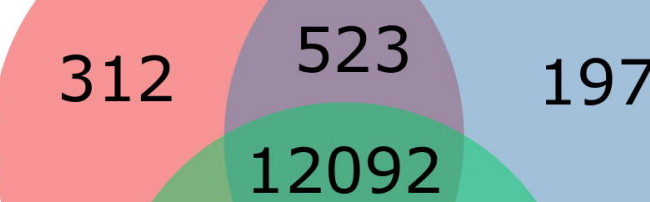

E

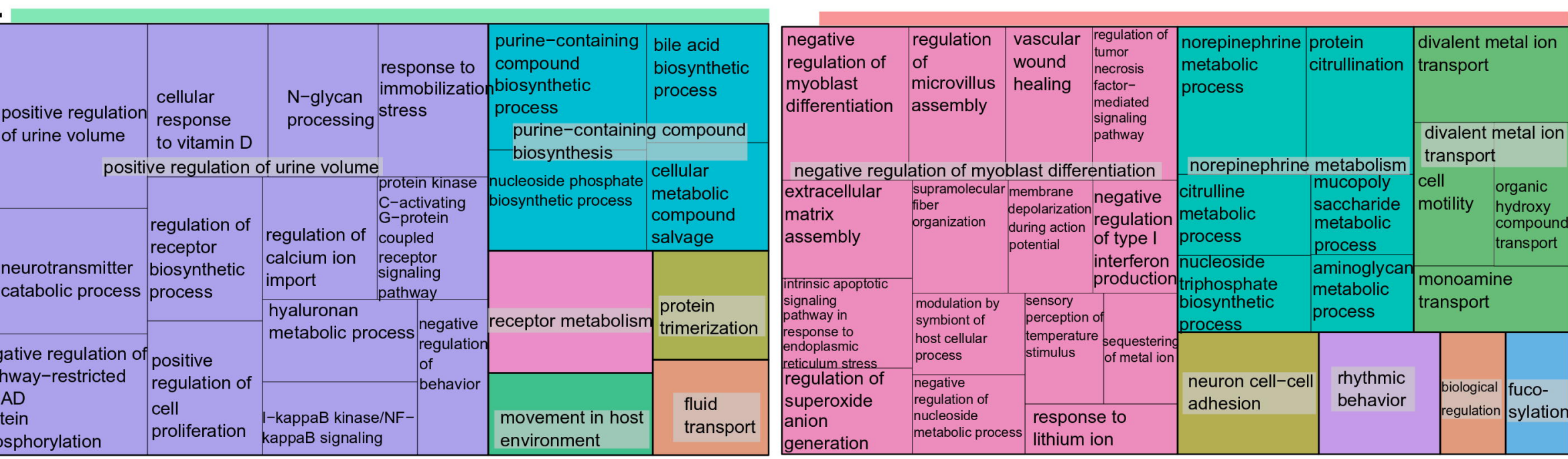




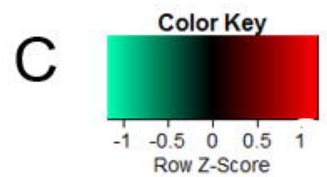

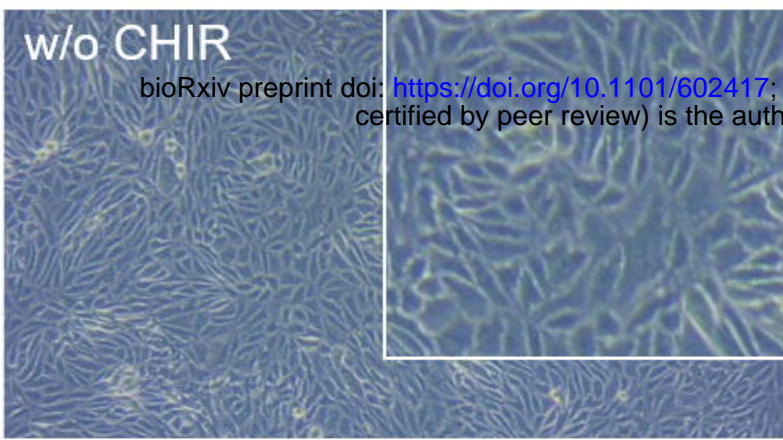

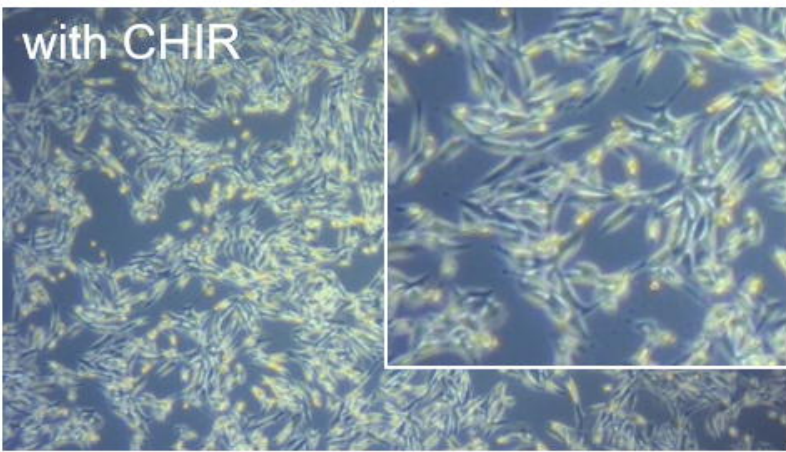

B

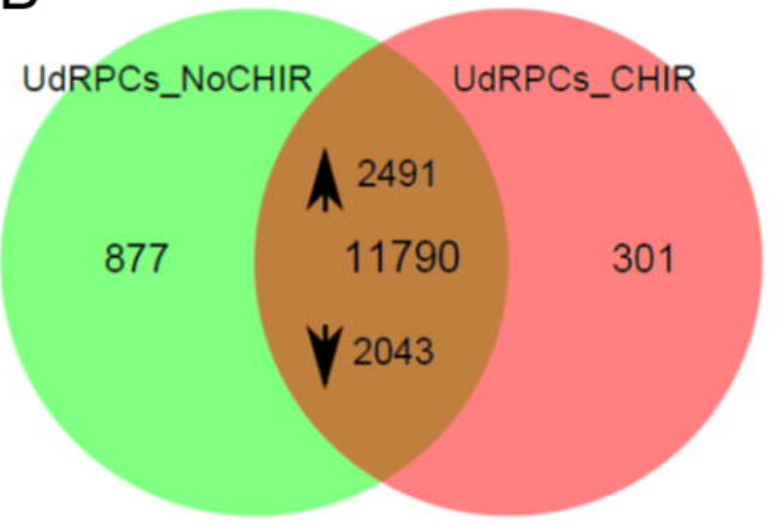

D

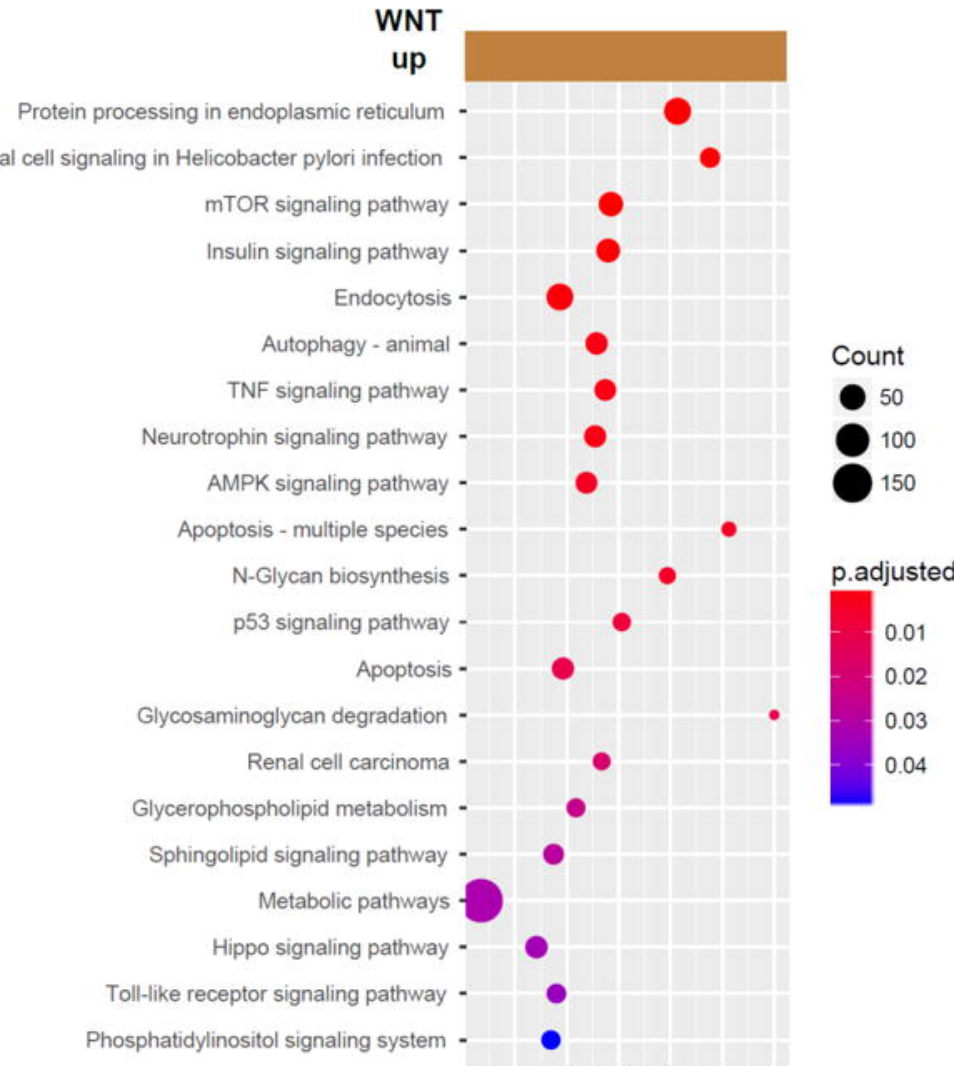

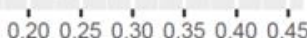
GeneRatio rsion posted April 8, 2019
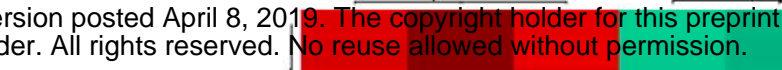

32455 at_KCNJ15 11718927_a_at ARID5B $11745803 \times$ at TPM1 11715493_a_at_CYR61 11734317_a_at_STARD8 11726023 a at EDN1 11722807 a at WDR54 11753666_x_at_PTN 11725069_s_at_PHF17 11718305_a_at_PDLIM2 11757621_a_at_MYLK 11716587_at_AXL 11725472_a_at_PAQR8 11745381 a at COBLL1 11734959_at_TRHDE 11749216_a_at_HAVCR1 11721738_a_at_LATS2 11717062_at_AP1M2 11735610_a_at_RPS6KA5 11751905_a_at_NID1 11739515 at CA8

11730880 a at NEBL 11734414_at_CALCB 11747981_a_at_APCDD1 11730036 at SP5

11743816_s_at S1PR1 11720022_a_at_MME 11763963_at_OTTHUMG00000173400 11735317_a_at_CACNB4 11730469 s at LMO2 11718396_x_at_JUN 11726455_x_at_MYO5B 11738157 a at GALNT9 11733327_at_NKD1

11728122_a_at_GPR64 11744315_at_SGK223 $11761790 \times$ at TRDC 11718452 at_AXIN2 11736575_x_at_GPR155 11748782 a at CASP9

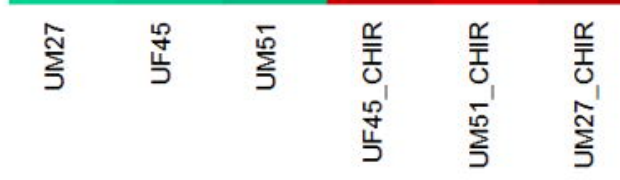

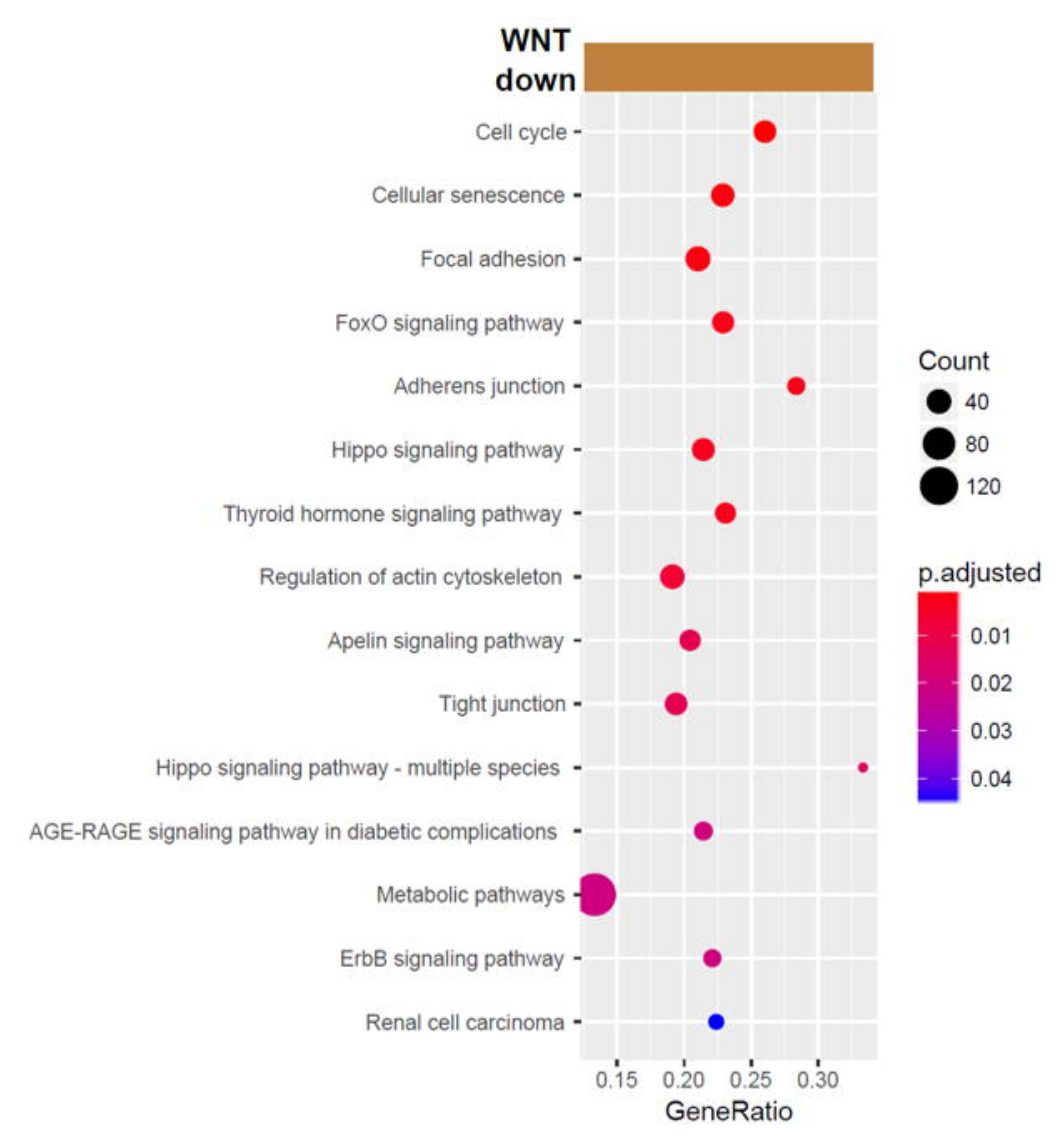


A

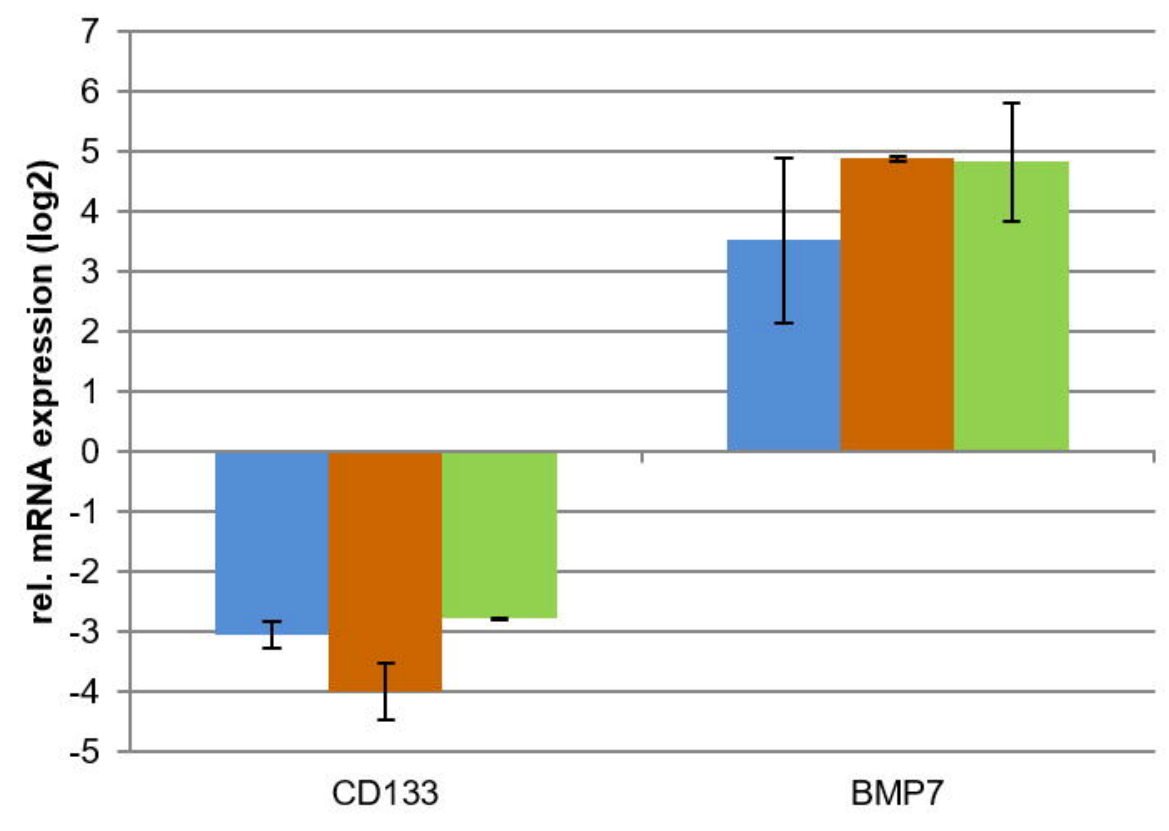

C

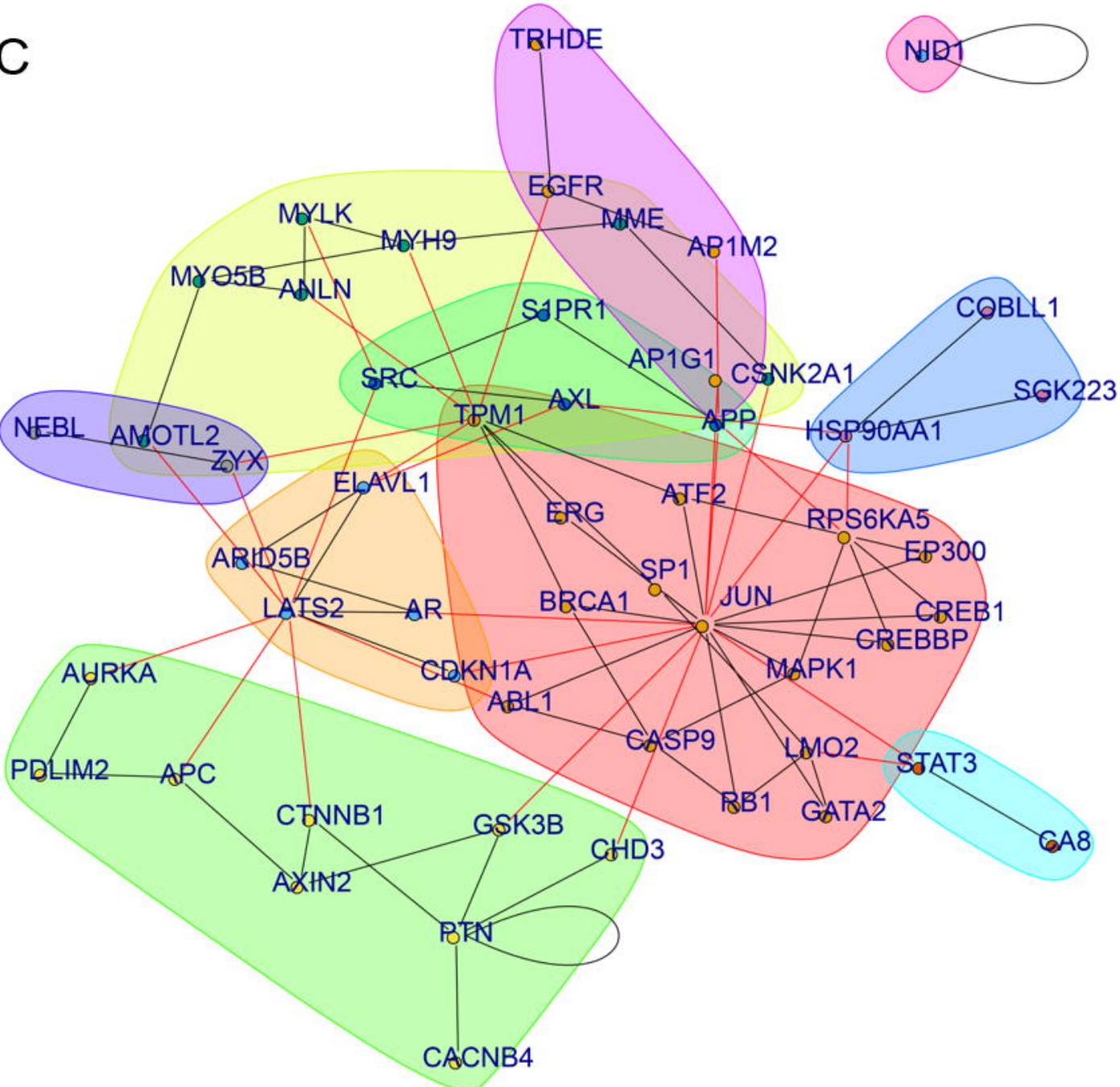

B

- UF45

- UM27

$=$ UM51

NEBL

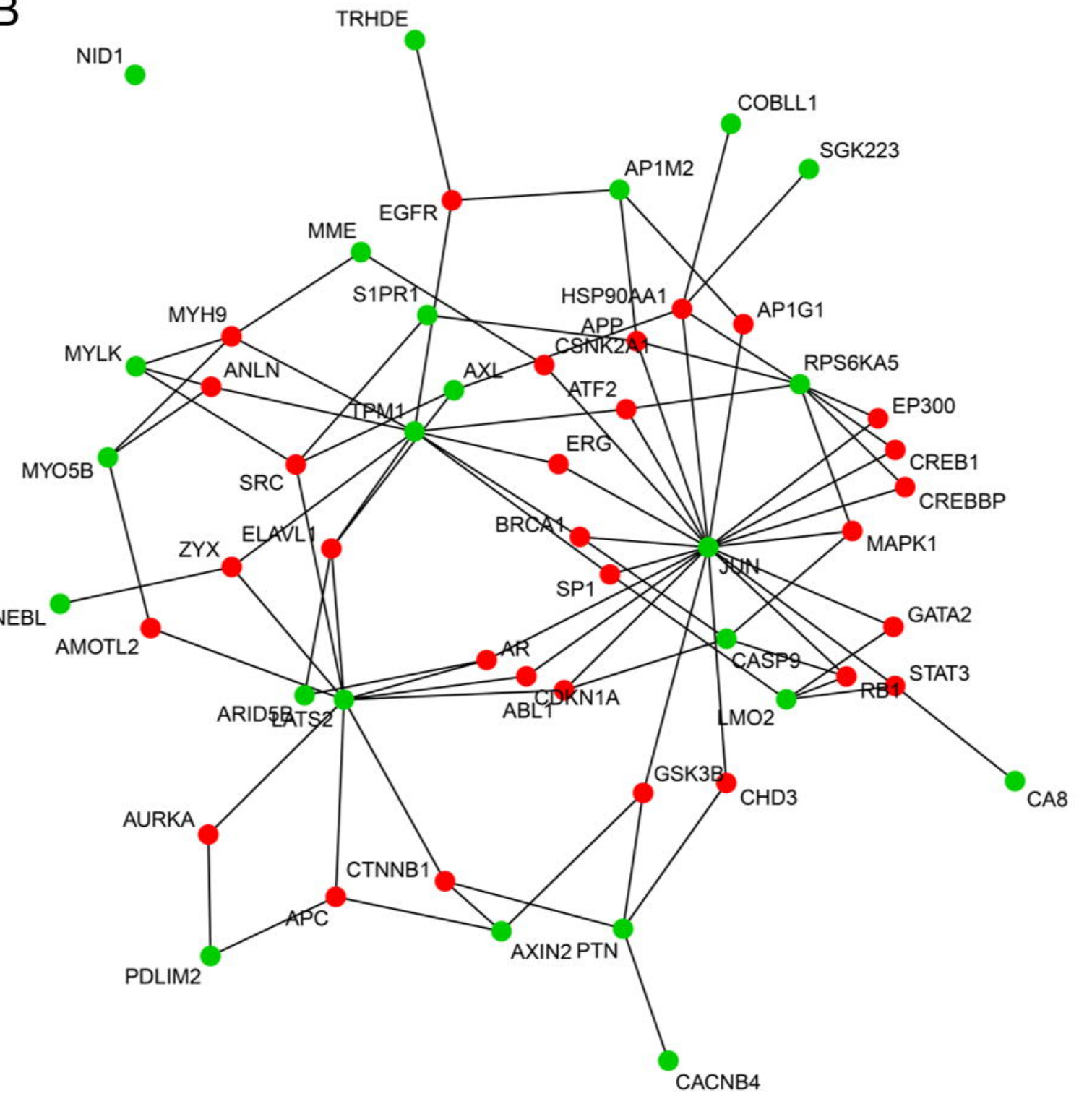

D $\frac{\text { UF45 }}{\text { CTR CHIR }} \frac{\text { UM51 }}{\text { CTR CHIR } \frac{\text { UM27 }}{\text { CTR CHIR }}}$ Phospho SMAD 2/3

$r=m$ Total SMAD 2/3

$\longrightarrow$ Phospho SMAD 1/5/8 


\section{GSK3 $\beta \longmapsto$ CHIR99021}

\section{WNT Signalling}

CD133 FGF2 WT1 TGF $\beta$ Pathway SIX2 CITED1

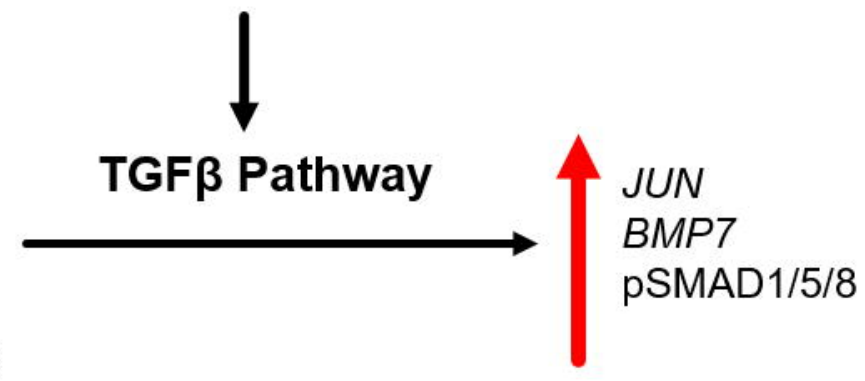
pSMAD2/3 